\title{
A mechanistic study of SCC in Alloy 600 through high-resolution characterization
}

\author{
Zhao Shen $^{\text {a }}$ Koji Arioka ${ }^{\text {b }}$, Sergio Lozano-Perez ${ }^{a, *}$ \\ ${ }^{a}$ Department of Materials, University of Oxford, Parks Road, OX1 3PH Oxford, UK \\ ${ }^{\mathrm{b}}$ Institute of Nuclear Safety Systems, Inc. (INSS), 64 Sata, Mihama-cho, Mikata-gun, Fuki, Mihama 919-
}

1205, Japan

Corresponding author: sergio.lozano-perez@materials.ox.ac.uk

\begin{abstract}
High-resolution characterization was used to understand the mechanisms controlling stress corrosion cracking (SCC) in Alloy 600 exposed to simulated PWR primary water conditions. Three potential active crack tips obtained from different types of grain boundaries were studied and compared. The results suggest that the dominant mechanism controlling SCC propagation is intergranular internal oxidation. The applied stress, preexistent residual strain, the accumulation of defects around the crack tip, the formation of a Fe-Cr-depleted zone, and a porous intergranular oxide are acknowledged as necessary precursors to SCC. Based on the results obtained in this study, a model of SCC propagation is proposed.
\end{abstract}

Keywords: Crack tip; Stress corrosion cracking; Internal oxidation; Alloy 600; Transmission electron microscopy; Transmission Kikuchi diffraction

\section{Introduction}

Nuclear energy has been treated as a kind of green energy since 1954 when the first nuclear-powered electricity generator started to operate in Obninsk, Russia. Thereafter, nuclear reactor began to be widely developed all around the world. Among all types of nuclear reactors, pressurized water reactors (PWRs) are the most commonly built [1]. Nickel-base Alloy 600 has been extensively used as components in the primary circuit of PWRs such as steam generator tubing and control rod driving mechanism nozzles because of its combination of excellent mechanical properties and high general corrosion resistance in high-temperature water $[2,3]$. However, stress corrosion cracking (SCC) failure of the low-chromium Alloy 600 in the low electrochemical potential primary water conditions, which is also known as primary water SCC, has been reported as early as in 1959 since the initial work of Coriou and coworkers [2]. Since then, failures were frequently reported in Alloy 600 components during long-term operation in PWR environment [3-5]. Although many phenomena related to the process of primary water SCC have been discussed [6-17], the controlling mechanisms are still unclear.

Grain boundaries could be classified into three categories based on their symmetry: low angle grain boundaries (LGBs), high angle grain boundaries (HGBs), and coincidence site lattice grain boundaries (CSLBs) [18]. Since most primary water SCC cracks in the Alloy 600 are intergranular and cracking susceptibility depends on grain boundary type $[6,8,9,19-21]$, to thoroughly understand the SCC mechanisms, it is necessary to discuss how SCC affects different kind of grain boundaries.

Results from literature [22-25] suggest that there is a strong relationship between the SCC behavior and the structure and chemistry around a crack tip. A promising way to identify this relationship was proved to be 
high-resolution characterization of the crack tip areas [6-14, 16, 25-27]. Meisnar et al. [27] successfully conducted high-resolution scanning transmission electron microscopy (STEM) analysis on the crack tip areas and discussed the roles of at least two mechanisms on the crack growth rates (CGRs) of 316 stainless steel (SS). Bruemmer et al. [6, 8] identified the processes of selective oxidation along grain boundary of Alloy 600 through TEM analysis on grain boundary oxide, indicating that a relatively low content of $\mathrm{Cr}$ at the grain boundary accelerates the intergranular oxidation which then increases the intergranular CGR. In addition, recent results suggest that there is a strong relationship between SCC susceptibility and grain boundary deformation [19, 28-35]. Since transmission Kikuchi diffraction (TKD) was first reported by Keller et al. [36] to be a technique working similarly to electron back scattered diffraction (EBSD) but that could significantly improve the spatial resolution to several nanometers in 2012, this technique has been used by several research groups in different fields [22, 27, 37-40]. Meisnar was the first one to use the TKD to quantify the localized deformation around the crack tip, showing the dislocations concentrated around the crack tips could lead to the embrittlement of the structure which then influenced the SCC propagation [22, 27]. This technique enables the direct measurement of the highly localized deformation around the crack tips, which seems very promising for understanding the mechanisms of SCC.

To date, several models have been proposed to explain the mechanisms of SCC, including film rupture model, hydrogen embrittlement model, and internal oxidation model [41-45]. Among them, the internal oxidation model, which was first introduced by Scott et al. [41] and further developed by following researchers $[26,27,46-48]$, is the one that seems to describe the degradation of Alloy 600 more realistically. In this model, the basic assumption is that when the potential is near the $\mathrm{Ni} / \mathrm{NiO}$ interface or in the Ni-stable region, intergranular oxidation resulting in the selective oxidation of $\mathrm{Cr}$ and $\mathrm{Fe}$ occurs. Then, the oxidized grain boundaries tend to crack more easily because of the embrittlement caused by the oxides. The brittle nature of the oxidized grain boundary has been experimentally proven by Dugdale et al. [12] and Fujii et al. [48] through directly measuring and comparing the mechanical strength of oxidized and intact grain boundaries.

The objective of this work is to mechanistically understand the SCC behavior of a mill-annealed Alloy 600 exposed to primary water of PWR at $320^{\circ} \mathrm{C}$ and to determine what precursors are required for SCC cracks to propagate. Although the literature in this topic is abundant, we believe that recent advances in characterization techniques are providing easier way to interpret the results that make revising this topic worth and allow for a mechanistic explanation based entirely on direct observations. Thus, through a better understanding of SCC mechanisms and precursors, better methods to predict the service lifetime and mitigate the cracking behavior of Alloy 600 can be devised.

\section{Experimental}

\subsection{Material and SCC test}

The material used in this study was Alloy 600 tested under simulated PWR primary water conditions by INSS (Japan) [45]. The chemical compositions and microstructures of this alloy are listed in Table 1 and Fig. 1. The grain boundary distribution is shown in Fig. 1a and the average grain size was around $120 \mu \mathrm{m}$. The kernel misorientation (KMO) map (see Fig. 1b) indicates that the deformation was uniform after cold-work. Grain boundaries with $\sum$ values ranging from 3 to 29 are treated as CSLBs, while grain boundaries $\sum 1$ and grain boundaries with $\sum$ values bigger than 29 are known as LGB and HGB, respectively. From Fig. 1a and c, it is clear that most of the CSLBs were $\sum 3$.

Table 1 Chemical content of the alloy used in this study (wt\%)

\begin{tabular}{cccccccccc}
\hline Material & $\mathrm{C}$ & $\mathrm{Cr}$ & $\mathrm{Fe}$ & $\mathrm{Si}$ & $\mathrm{Mn}$ & $\mathrm{P}$ & $\mathrm{S}$ & $\mathrm{Cu}$ & $\mathrm{Ni}$ \\
\hline Alloy 600 & 0.06 & 16.02 & 6.94 & 0.33 & 0.35 & 0.006 & $<0.001$ & 0.03 & 76.26 \\
\hline
\end{tabular}




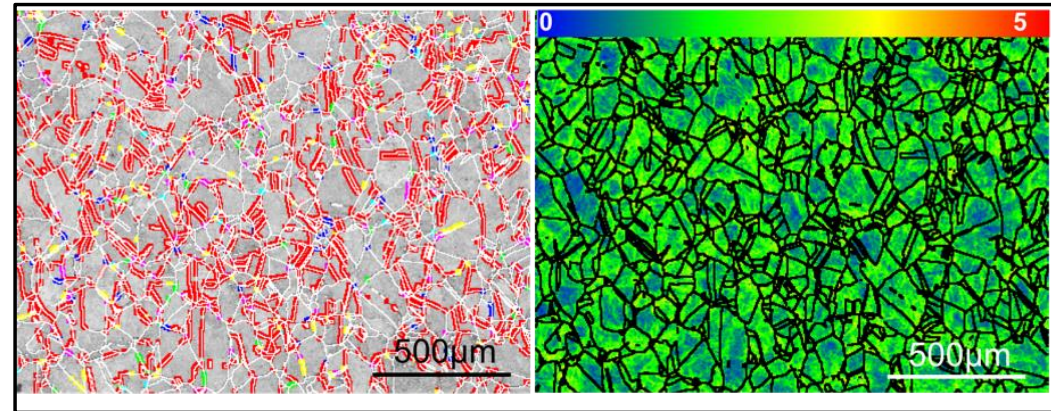

(a) (b)

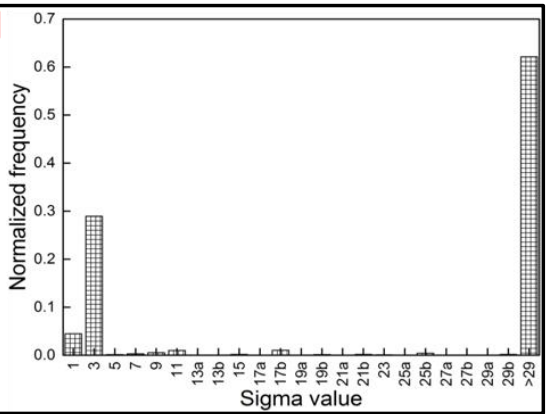

(c)

Fig. 1. Microstructure of Alloy 600 obtained from EBSD (step size $=4 \mu \mathrm{m}$ ) analysis. (a) Distribution of grain boundaries ( $\sum 3$ in red, HGB in white); (b) KMO map; (c) grain boundary character distribution.

Prior to autoclave testing, the specimen was mill-annealed in air at $930^{\circ} \mathrm{C}$ followed by water quenching. Cold-work in austenitic alloys was shown to be detrimental to SCC, however, it is inevitable during manufacturing and installation [28, 29, 49]; therefore, in order to simulate the real working condition of Alloy 600 in a PWR, the specimen was cold-worked prior to the autoclave testing. Cold work in the specimen was produced through uni-directional rolling at room temperature to a thickness reduction of $20 \%$, which was also referred to as $20 \%$ cold work. The SCC test was conducted by INSS (Japan) using a pre-cracked 0.5 T compact tension (CT) specimen in the T-L direction (crack growth direction parallel to the rolling direction) in an autoclave under a constant load of $30 \mathrm{MPa} \mathrm{m}^{1 / 2}$ at $320^{\circ} \mathrm{C}$. More details can be found in [45]. It is necessary to point out that the content of dissolved hydrogen used in this test $\left(30 \mathrm{~cm}^{3} / \mathrm{kg}\right)$ located at the Ni-stable region, which means it is difficult for the Ni to be oxidized during the SCC testing [5]. The measured CGR was around $5.6 \times 10^{-7} \mathrm{~mm} / \mathrm{s}$. Before destructive examination of the fracture surface, one piece of cross-section sample was cut out from the CT sample after autoclave testing. This cross-sectioned sample was then ground with $\mathrm{SiC}$ paper, followed by polishing with 1- $\mu$ m diamond suspension. A mirror-finished surface was obtained after 15 minutes of final treatment with colloidal silica in order to reveal the location of the SCC crack tips.

\subsection{Methodology}

\subsubsection{Site-specific sample preparation with FIB}

Sample preparation was reported to be critical for the data quality obtained from (S)TEM and TKD analysis [22, 36, 37]. For example, electron energy loss spectroscopy (EELS) requires the sample thickness to be around $50 \mathrm{~nm}$ while the TKD analysis needs similar thicknesses without sample bending. To study specific crack tips, the FIB plan-view sample preparation technique was adopted in this study. A single beam FEI FIB200 equipped with a static micromanipulator was used for trenching and in-situ lift-out. A dual beam Zeiss NVision 40 FIB-SEM was subsequently used for thinning sample to a thickness less than 50nm. Since FIB milling could introduce significant damage on the sample surface, final low energy cleaning ( $5 \mathrm{kV}, 250$ pA) with FIB should be performed on both sides of the thin foil after a conventional milling to minimize the damage. More details can be found in [50].

\subsection{2 (S)TEM analysis}

Once crack tip samples were prepared, TEM analysis was performed with a JEOL 2100 (operating voltage $200 \mathrm{kV}$ ) for TEM imaging and selected area diffraction. Higher-resolution analysis, including STEM and EELS, was conducted with a JEOL ARM200F (cold-filed emission gun) operating at $200 \mathrm{kV}$ and equipped with a Quantum Gatan image filter (GIF) spectrometer. EELS spectra (low- and core-loss) were acquired correcting the spatial drift and recalibrated in energy using the zero loss peak as a reference. Principal components analysis (for denoising) was performed using Hyperspy 1.1 (open source) software. The convergence and collection half-angles were 31 and $41 \mathrm{mrad}$, respectively. EELS quantification was performed in Digital Micrograph by the background subtraction method. The relatively low thickness of all areas analyzed $(\sim 50 \mathrm{~nm})$ allow for a reliable quantification without removing plural scattering. This was 
checked for regions of known composition (e.g. matrix). Relative errors in EELS quantification were dominated by uncertainties in theoretical cross-sections and can be assumed to be $\sim 10 \%$ for most measurements.

\subsubsection{TKD analysis}

TKD analysis was performed using a Zeiss Crossbeam 540 FEG-SEM equipped with Oxford Instrument (OI) EBSD NordlysMax 3 detector system. The sample was $20^{\circ}$ pre-tilted with respect to horizontal, and the working distance was set to $5 \mathrm{~mm}$. An accelerating voltage of $20 \mathrm{kV}$ and a probe current of $1.5 \mathrm{nA}$ were used. The step sizes were set to $10 \mathrm{~nm}$. The data was subsequently post-processed by the OI software Channel 5 . Image quality, MO, and inverse pole figure (z-axis) (IPFZ) maps were calculated automatically by the software, and MO line profiles extracted manually.

\section{Results}

\subsection{General microstructure features}

Optical micrographs of CT specimen of Alloy 600 after autoclave testing at $320^{\circ} \mathrm{C}$ were used for locating active crack tips at the deepest part of SCC cracks, as shown in Fig. 2a. Fig. 2b shows how the specimen was extracted in T-L direction, which means the crack growth direction was parallel to the cold-rolling direction. The fatigue crack was strictly parallel to the notch direction with no interruption, whereas the SCC cracks were generally parallel to the notch direction, and they were not continuous in 2D (along the polished crosssection, see Fig. 2a). In addition, since the SCC susceptibility of Alloy 600 in PWR primary water was very high, almost all intersected HGBs in the wakes of primary cracks were cracked. Therefore, this specimen showed extensive branching, as shown in Fig. 2c.

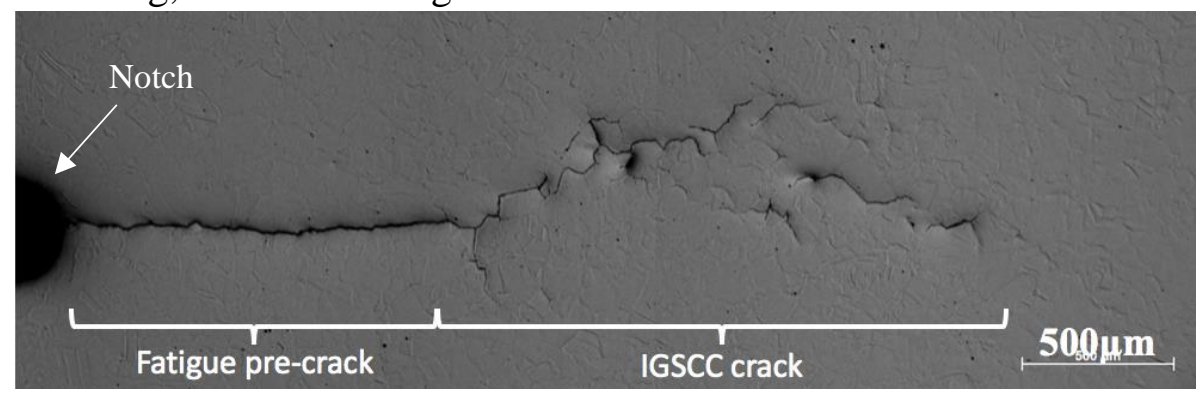

(a)

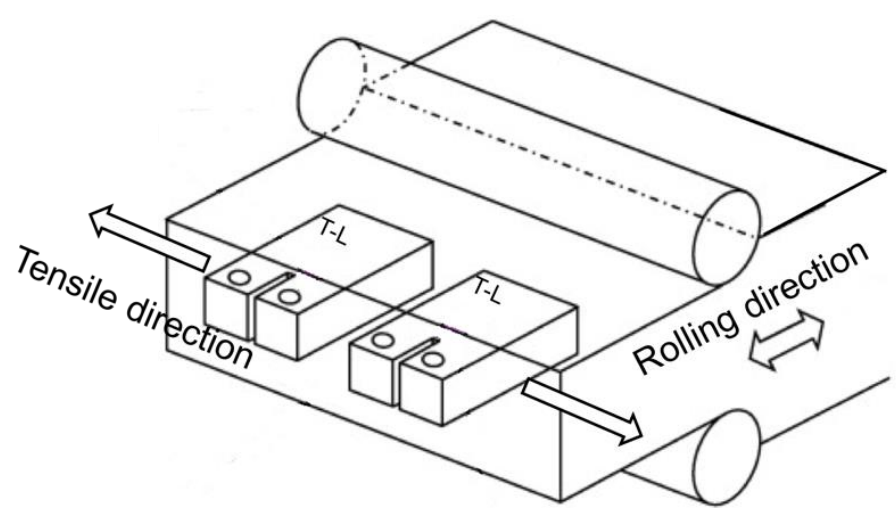

(b)

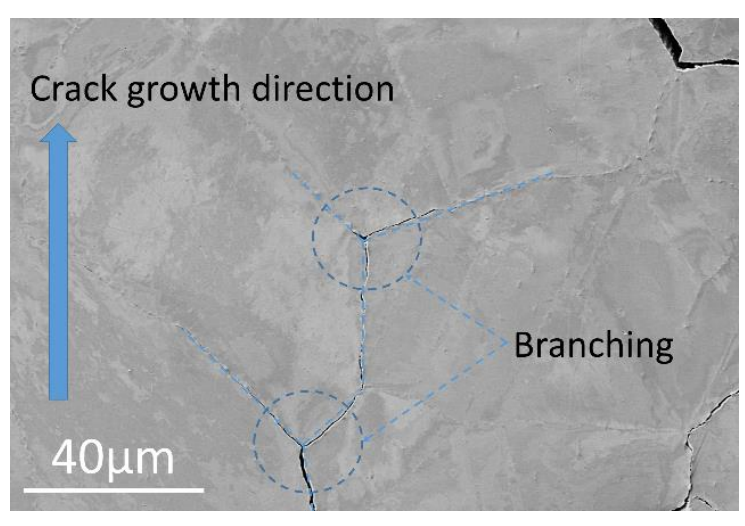

(c)

Fig. 2. a) Optical micrograph of cross-sectional surface of Alloy 600 tested at $320^{\circ} \mathrm{C}$; b) illustration of $20 \%$ cold-worked 1/2T CT specimen tested in T-L orientation; c) example of SEM image showing the branching feature.

The heat treatment used for this material leads to the formation of numerous carbides. The preliminary EDX results indicated that the carbides were composed of $\mathrm{Cr}$ and $\mathrm{C}$ (not shown). The representative 
distribution of $\mathrm{Cr}$ carbides at grain boundaries is shown in Fig. 3. Most of the carbides were elongated and randomly distributed along the grain boundaries. The average grain boundary coverage of the precipitates was around $20 \%$. Intergranular carbides also appeared on twin $\left(\sum 3\right)$ boundaries, though the density was much lower than on HGBs. In addition, a large number of intragranular carbides were discovered. The intergranular and intragranular carbides were identified as $\mathrm{Cr}_{7} \mathrm{C}_{3}$ by electron diffraction. Voids were occasionally observed near the intergranular carbides and are believed to have formed during cold working [6]. Their potential role in SCC is still unclear and will not be discussed in this paper.

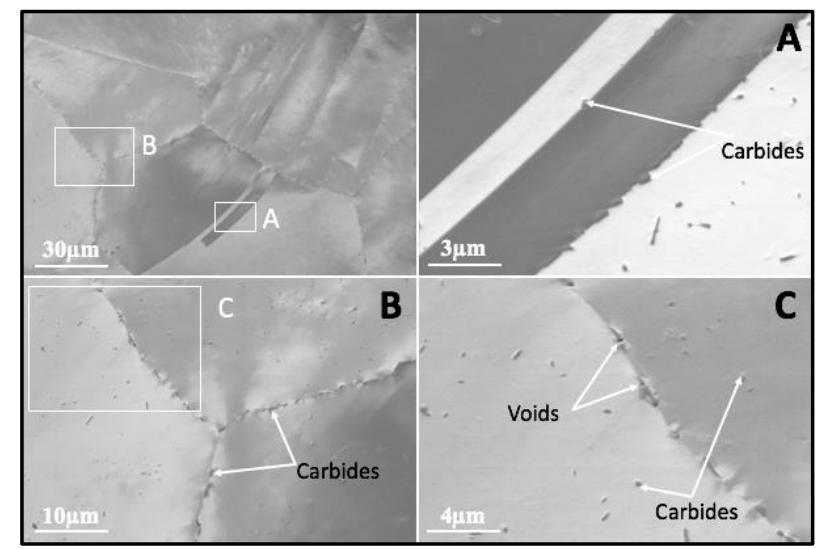

Fig. 3. Examples of FIB-SEM SE images showing the carbides distribution at grain boundaries.

\subsection{High-resolution (S)TEM characterization}

SCC susceptibility of grain boundaries varies with grain boundary character $[6,8,9,18-20]$. These differences were believed to be due to different grain boundary energies [8, 19]. In this study, three different kind of grain boundaries were examined in order to identify the effect of grain boundary character on SCC. Twin boundaries $\left(\sum 3\right)$ were not included because none was found to be SCC-attacked in this material. In this work, EBSD was first used to identify grain boundary characters of SCC-attacked boundaries. FIB was then utilized to prepare high-quality TEM samples containing crack tips. Three potentially active crack tips were selected at the deepest cracking area, including along a LGB $\left(\sum 1\right)$, a CSLB $\left(\sum 25 b\right)$ and a HGB $\left(\sum>29\right)$. The $\sum 25 \mathrm{~b}$ was the chosen as the only one in the CSLB category $\left(3<\sum \leq 29\right)$ with a potentially active crack tip. The reason why only the deepest crack tips were used in this study is because they were most likely to still be active, and exposed to PWR water for similar times when they were taken out from the autoclave. This precondition is indispensable to directly compare the features observed around different crack tips because different exposure time can change both structure and chemistry around crack tips. Since this is just an assumption, differences caused by the different exposure times might still exist.

\subsubsection{SCC-attacked LGB $\left(\sum 1\right)$}

The structure around the crack tip of the SCC-attacked LGB is presented in Fig. 4. A porous zone ahead of the crack tip was observed, which is consistent with previous reports in the literature [8-11]. In order to study the porosity, Fresnel contrast TEM imaging was used. More details about the Fresnel contrast imaging can be found in [8]. As shown in Fig. 4a-c, the pores were almost invisible in the focused image (see Fig. 4b), whilst clearly visible in the underfocused and overfocused images (Fig. 4a and 4c). In order to conveniently show the porous structure, all the TEM images in this paper were in purposely taken at underfocused condition, highlighting the porous structure as brighter features. The defocus value varied with the image magnification from $\pm 800 \mathrm{~nm}$ to $\pm 1200 \mathrm{~nm}$. After studying the Fresnel contrast images (see Fig. $4 \mathrm{a}$ and $4 \mathrm{c}$ ), the crack developed along the LGB can be divided into two parts, the open crack zone and the oxidized uncracked zone. The oxidized uncracked zone was also known as intergranular oxidation zone (IOZ) because it was thought to be formed by the diffusion of oxygen along the grain boundary during the SCC propagation [8-11]. The existence of IOZ ahead of the tip of SCC cracks is one of the characteristic features supporting the SCC 
mechanism of internal oxidation proposed by Scott and Le Calvear [41, 51]. The crack opening of the open crack zone was very small (less than $20 \mathrm{~nm}$ ), especially at the interface area of the open crack zone and the IOZ (see Fig. 4a). According to the results reported in [11, 12, 48], oxygen diffusion can significantly promote the SCC susceptibility, and the intergranular oxidation is an important factor that is responsible for SCC. As a result, the length of the IOZ was adopted as one of the parameters describing the SCC susceptibility of a specific grain boundary. Fig. 4a shows that the IOZ length was around $91 \mathrm{~nm}$. A high-quality TEM sample preparation by FIB might enable a more detailed observation than those from samples prepared by traditional methods $[6,8]$. Fig. $4 \mathrm{~d}$ shows the high density of pores at the interface area of the open crack zone and the IOZ, indicating that the crack propagates by breaking the brittle IOZ. Fig. 4e shows the leading edge of the IOZ at a higher magnification. It is possible to see pores (diameter $\sim 1.2 \mathrm{~nm}$ ) in the IOZ. Selective area diffraction (SAD) was conducted on the IOZ and both $\mathrm{Cr}-\mathrm{Ni}$ spinel oxides and $\mathrm{NiO}$ were found (see Fig. 4e), which is consistent with the literature $[8,10,11]$. In addition, discretely distributed $\mathrm{Cr}_{2} \mathrm{O}_{3}$ was also observed via high resolution TEM (HRTEM), as shown in Fig. 4f.

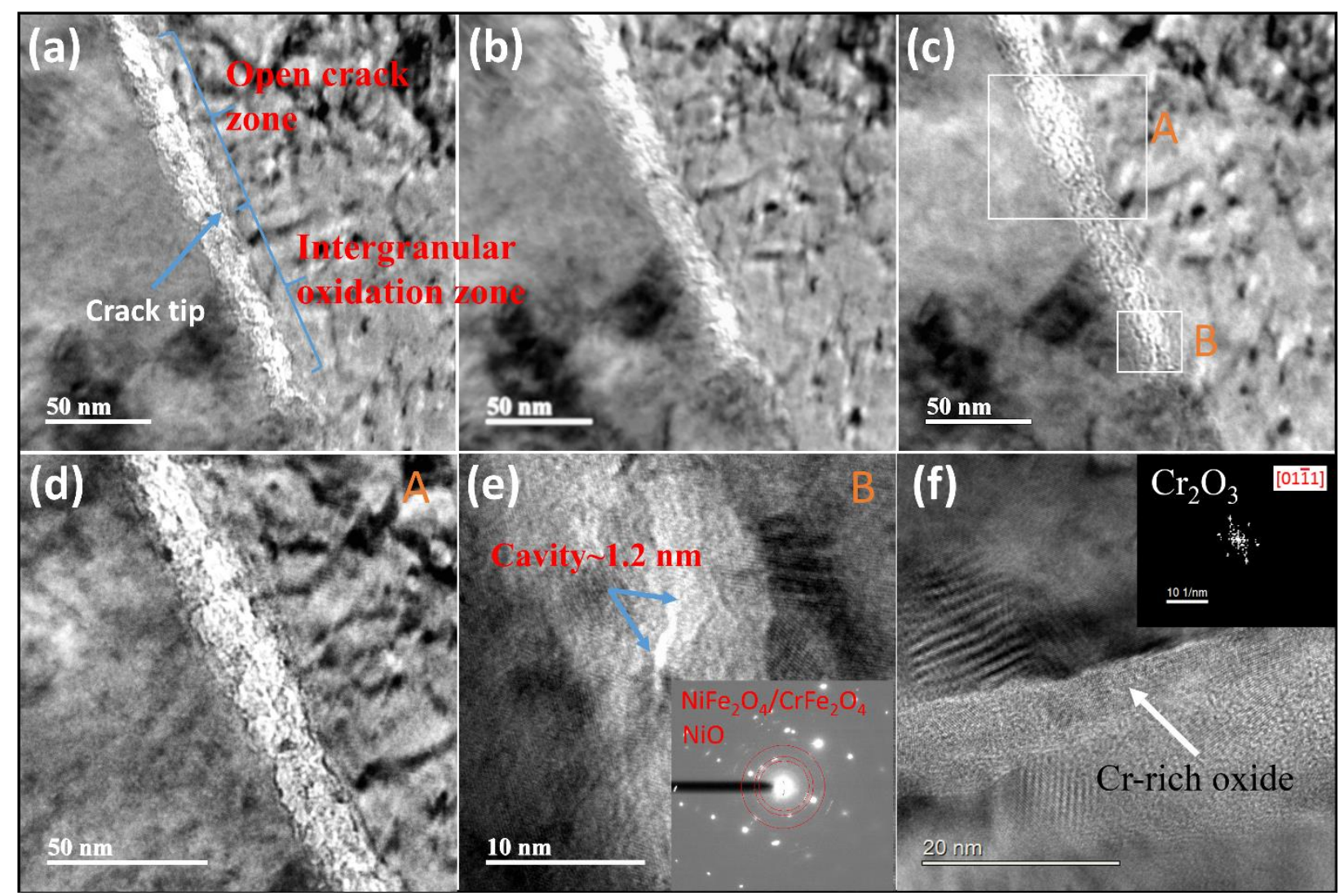

Fig. 4. Fresnel-contrast TEM images taken at (a) underfocused, (b) focused, and (c) overfocused conditions to reveal porous structure; (d) magnified view of the rectangle area A in (c); (e) magnified view of the rectangle area B in (c); (f) .

The specimen used in this study was $20 \%$ cold-worked, but regions around crack tips could have been further deformed by the external load applied to the specimen during SCC testing. The high defect densities around the crack tip region could significantly mask some microstructural aspects under TEM observations. However, the combination of TEM and STEM high angle annular dark-field (HAADF) helped to improve the understanding of the structures in the open crack zone and the IOZ. Fig. 5a shows part of the open crack zone, the entire IOZ, and part of the uncracked grain boundary. These different regions can be more easily distinguished by HAADF imaging than by Fresnel contrast in TEM mode, since the HAADF image is very sensitive to the atomic number, thickness and sample density. Assuming a local uniform thickness and density, darker means lower atomic density. This assumption has been proved by calculating and comparing the local 
sample thickness. In this sample, the signal intensity in the IOZ was slightly lower than in the uncracked grain boundary because when the oxygen diffused into the grain boundary, it firstly oxidized a part of the active metallic elements ( $\mathrm{Cr}$ and $\mathrm{Fe}$ ) and then the compressed stress caused by the formation of oxide pushed the more noble metallic elements $(\mathrm{Ni})$ into the surrounding material, leading to the reduction of average atomic number in this region. The signal intensity in the open crack zone was much lower than in the IOZ, indicating this region has been more severely oxidized.

To see the elemental distribution near the crack tip, EELS elemental mapping was conducted. The step size of this test was set at $1.5 \mathrm{~nm}$. In the Fig. 5b, no metallic depletion or enrichment was observed in the grain boundary far from the crack tip, but there was a $\mathrm{Cr}$-Fe depleted associated with Ni-enrichment zone just ahead of the leading edge of the IOZ. The length of this Cr-Fe depleted zone was around $95 \mathrm{~nm}$. Since Cr-depletion in the grain boundary is detrimental to SCC $[6,10,11]$, the length of the $\mathrm{Cr}-\mathrm{Fe}$ depleted zone was selected as another parameter to describe the SCC susceptibility of a specific grain boundary. This Cr-Fe depleted zone was not only detected in Ni-based alloys but also in stainless steels [6, 9-11, 26, 52]. The outward diffusion of $\mathrm{Cr}$ and $\mathrm{Fe}$ to form thermodynamically favourable oxidized species results in dealloying and the formation of a Ni-rich region $[6,10,11]$. It is interesting to note that a very thin layer of Cr-rich oxide existed at the tip of the IOZ, just behind the $\mathrm{Cr}-\mathrm{Fe}$ depleted zone. The $\mathrm{Cr}$ in this localized $\mathrm{Cr}$-rich oxide is thought to come from the $\mathrm{Cr}$-Fe depleted zone ahead of it $[6,10,11]$. The atomic ratio in this area indicated that this $\mathrm{Cr}$-rich portion is likely to contain localized $\mathrm{Cr}_{2} \mathrm{O}_{3}$, together with $\mathrm{Ni}$ - and $\mathrm{Cr}$-rich spinel. The presence of $\mathrm{Fe}$ and $\mathrm{Ni}$ might be due to the projection effect in TEM samples and the presence of other spinel oxides. Although the thickness of this Cr-rich layer was not uniform and the average thickness was only around $10 \mathrm{~nm}$, further oxygen diffusion seems to have been effectively prevented by this Cr-rich oxide film. Further EELS mapping revealed that the distributions of metallic elements were not uniform. Some Ni-rich and Cr-rich regions were observed in both the open crack zone and IOZ. These discrete regions were also observed by Langelier et al. [16] through 3D atom probe tomography (APT) and by Sennour et al. [10] through high-resolution TEM. These authors believed that the inward diffusion of oxygen into the matrix preferentially reacted with $\mathrm{Cr}$ and $\mathrm{Fe}$ forming internal oxide precipitates and, through dealloing, Ni-enriched regions formed.

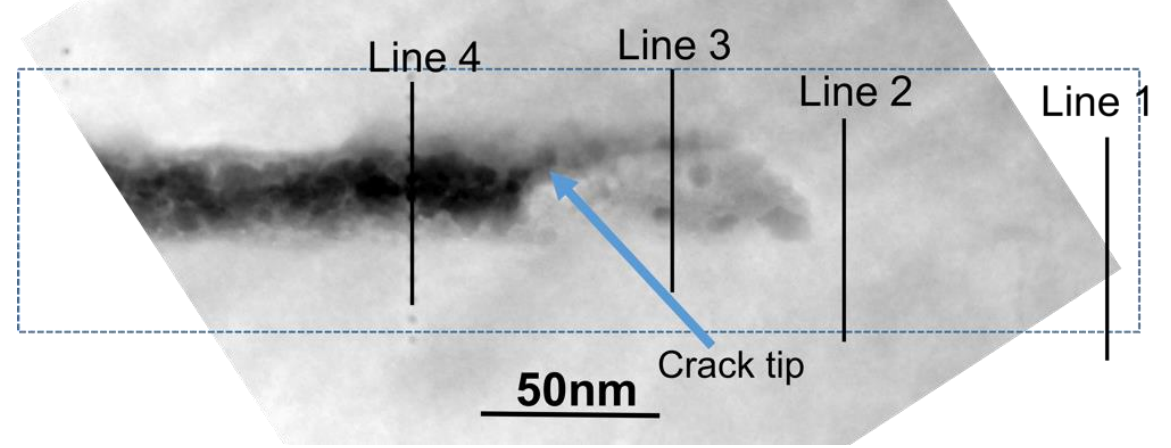

(a)

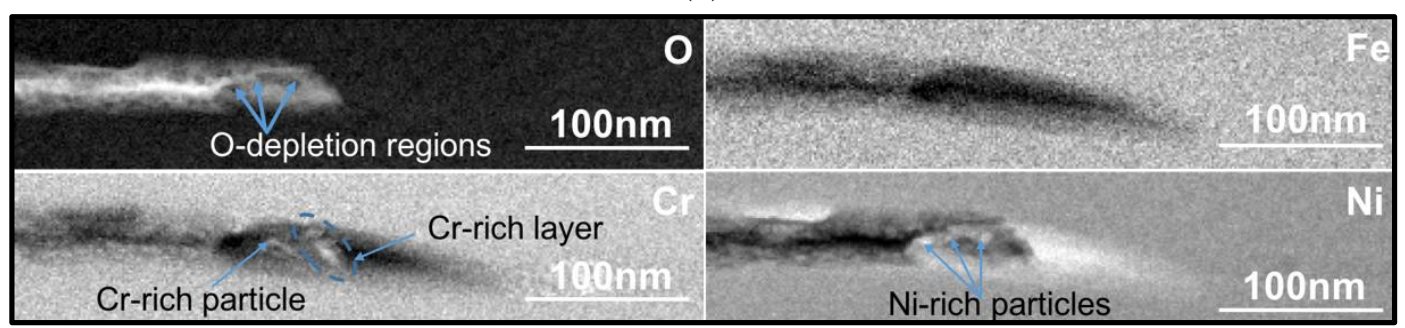

(b) 


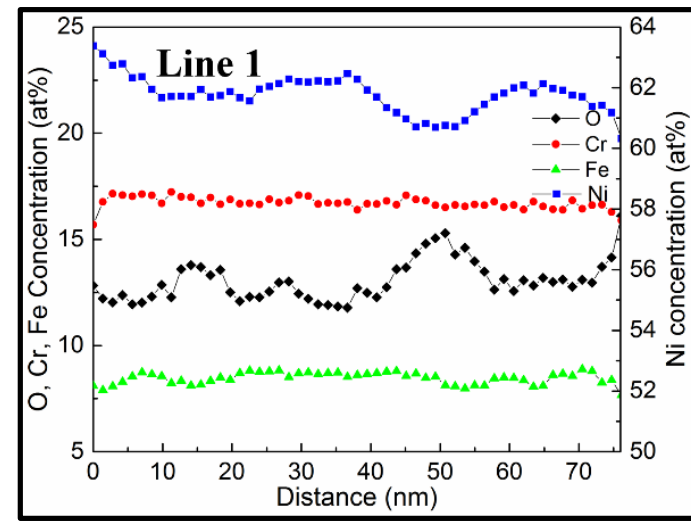

(c)

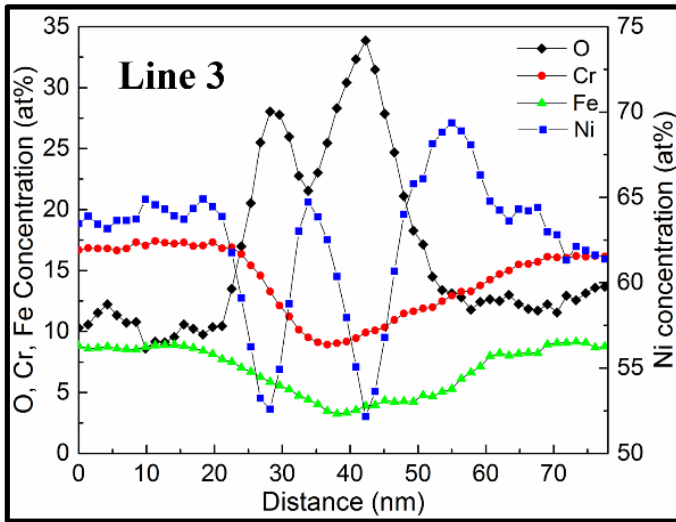

(e)

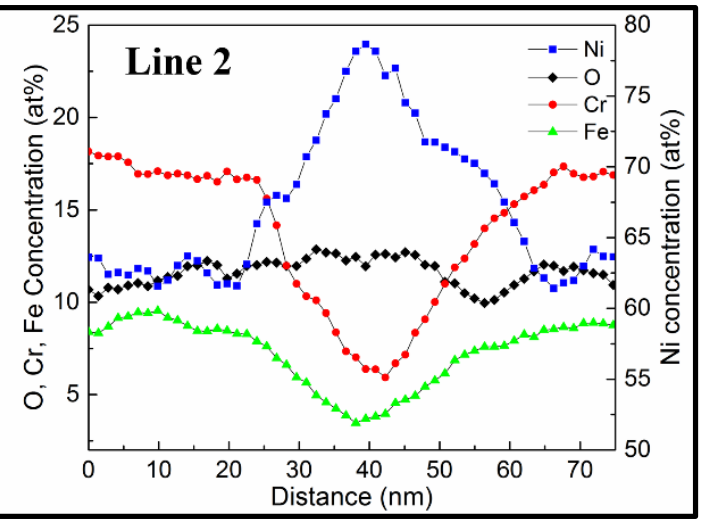

(d)

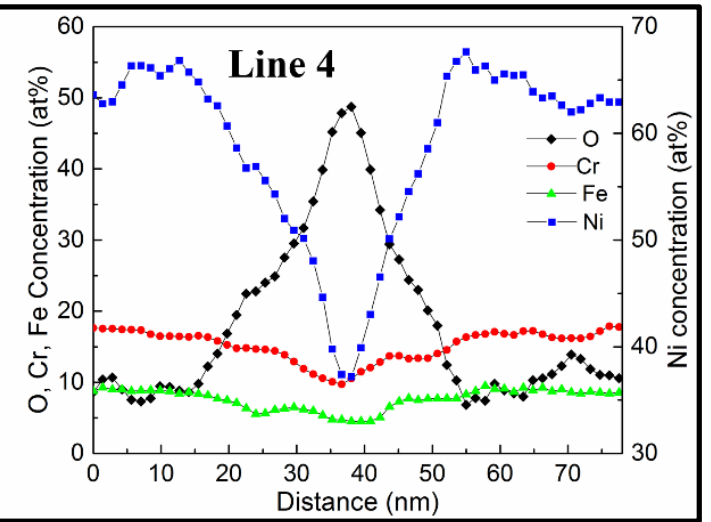

(f)

Fig. 5. (a) STEM-HAADF image of LGB crack tip with indication of EELS line-scanning locations; (b) EELS elemental $\mathrm{O} \mathrm{K}$ edge and $\mathrm{Cr} / \mathrm{Fe} / \mathrm{Ni}$ L edge maps (step size $=1.5 \mathrm{~nm}$ ) with relative error lower than $10 \%$; Composition line profiles obtained through EELS analysis performed at the grain boundary far from crack tip(c); just ahead of the leading edge of IOZ (d); at the IOZ (e); at the open crack zone (f).

To quantitatively show the elemental distribution around the crack tip, several EELS line-scans were conducted. The EELS line-scan locations are shown in Fig. 5a, (to clarify, the actual position of line 1 was about $300 \mathrm{~nm}$ ahead of the tip of the IOZ) and the corresponding compositional profiles are exhibited in Fig. $5 \mathrm{c}-\mathrm{f}$. The typical relative errors of the EELS quantification were around $10 \%$. The results from the Fig. $5 \mathrm{c}$ and $5 \mathrm{~d}$ were consistent with the Fig. 5b. Several line-scans were conducted through the IOZ. One typical result is shown in Fig. 5e, showing that the content of oxygen was much higher while the Ni content was much lower at the IOZ-metal interfaces, indicating this zone was preferentially oxidized. The oxidized region is believed to be more brittle under an external-load because a crack was found to propagate along the IOZ-metal interface (see Fig. 5a). A similar observation has been reported by Dugdale et al. [12] and Dohr [47]. According to the results reported in the literature [8-10], the oxide formed on the crack flanks could be divided in two layers: the outer layer consisted of $\mathrm{NiO}$ oxide (or Ni-rich spinel if below $\mathrm{NiO}$ stability potential), while the inner oxide layer was mostly $\mathrm{Ni}\left(\mathrm{Fe}_{\mathrm{x}}, \mathrm{Cr}_{1-\mathrm{x}}\right)_{2} \mathrm{O}_{4}$ spinel. In our study, the hydrogen concentration was high enough in the water to keep it on the Ni-stability region [5]. $\mathrm{Ni}\left(\mathrm{Fe}_{\mathrm{x}}, \mathrm{Cr}_{1-\mathrm{x}}\right)_{2} \mathrm{O}_{4}$ spinel was predominantly observed as the inner oxide on the crack flank according to the EELS line-scanning, as shown in Fig. 5f, with traces of $\mathrm{NiO}$ in the outer layer confirmed by electron diffraction (see Fig. 4e). The presence of $\mathrm{NiO}$ might be explained if it formed as the specimen cooled down or while in storage.

\subsubsection{SCC-attacked CSLB $\left(\sum 25 b\right)$}

Fig. 6 shows the morphology around the active crack tip in a CSLB $\left(\sum 25 \mathrm{~b}\right)$. From the Fresnel contrast images (Fig. 6a-c), a porous IOZ ahead of the crack tip was observed. The lengths of the IOZ was around 150 $\mathrm{nm}$. Cavities were observed in the IOZ and the average diameter was measured to be around $1.4 \mathrm{~nm}$. Similarly 
to the LGB, the crack also propagated along the IOZ-metal interface. The structure in the open crack zone was not uniform, consisting of a region with a small crack opening (see Fig. 6e) and a region with a bigger crack opening (see Fig. 6f). In this study, these two regions are defined as a narrow crack zone and a wide crack zone. The different crack opening widths, narrow crack zone and wide crack zone, might be partially caused by the different exposure time to the PWR water or from a 3D projection artefact. Fig. $6 \mathrm{~d}$ and $6 \mathrm{e}$ show that the structure in the narrow crack zone was much more porous than in the IOZ. This might be because the direct contact of the narrow crack zone with the water lead to higher oxidation (higher oxygen potential).

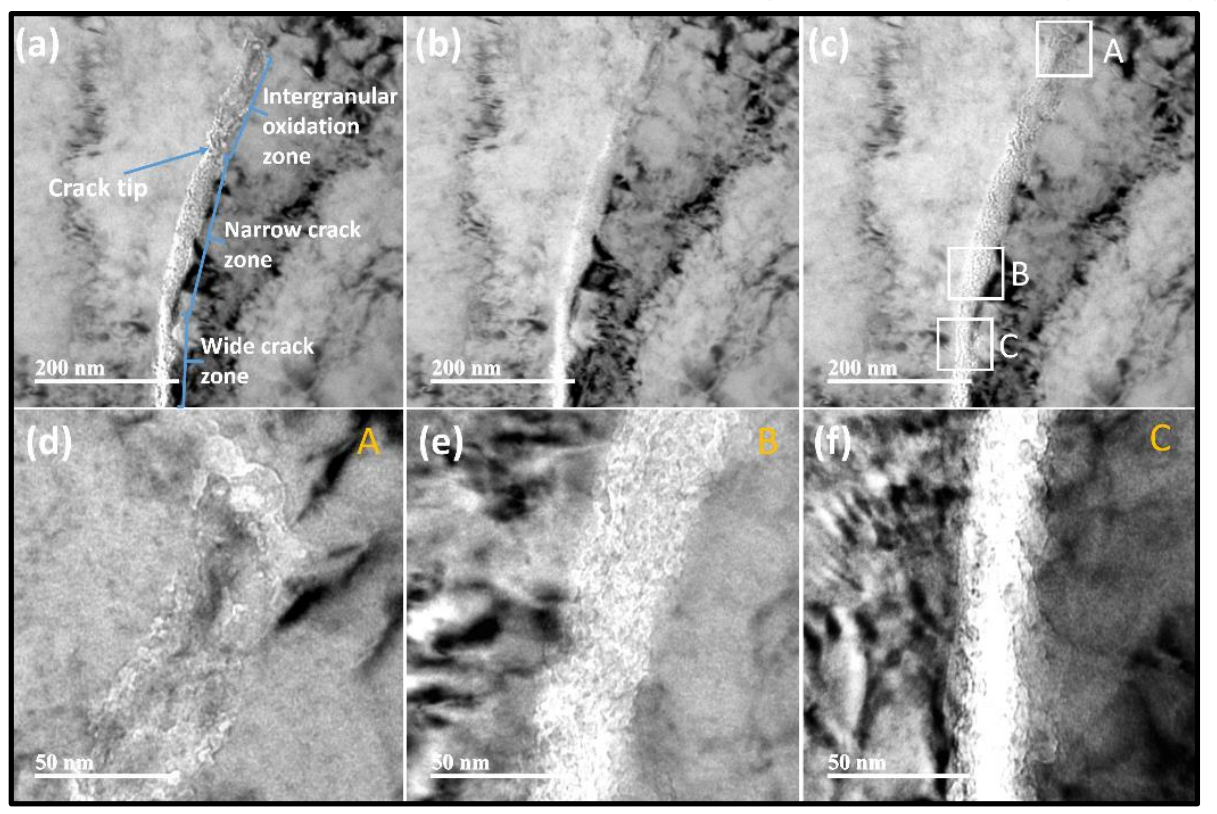

Fig. 6. Fresnel-contrast TEM images taken at (a) underfocused, (b) focused, and (c) overfocused condition to reveal porous structure; (d) magnified view of the rectangle area A in (c); (e) magnified view of the rectangle area $\mathrm{B}$ in (c); (f) magnified view of the rectangle area $\mathrm{C}$ in (c).

Fig. 7a shows a HAADF image around the crack tip. The signal intensity in the narrow crack zone was lower than in the IOZ, indicating that the narrow crack zone has suffered a greater extent of oxidation than the IOZ. As observed in Fig. 6, the crack propagated along the IOZ-metal interface, which also showed a lower signal intensity (see Fig. 7a). If the autoclave test had run for a longer time, it is believed that the crack would have propagated along this darker line. Another lower signal intensity zone was observed at the tip of the IOZ, indicating this region has suffered a higher extent of oxidation. This hypothesis is supported by the EELS maps (step size $=1.5 \mathrm{~nm}$ ) in Fig. 7b, showing that this region was $\mathrm{Cr}$ - and O-rich but depleted in Ni and Fe. The high $\mathrm{Cr}$ content suggests that some of the oxide formed in this region was $\mathrm{Cr}_{2} \mathrm{O}_{3}$. The EELS O-map shows that the oxygen diffusion was effectively stopped by the Cr-rich oxide film. Fig. 7b shows that the "original" grain boundary further away from the crack tip was slightly depleted in $\mathrm{Cr}$ and enriched in $\mathrm{Ni}$, which might be caused by the precipitation of carbides (see Fig. 3) [11, 14]. In contrast, the region just ahead of the tip of the IOZ was much more Cr-Fe depleted and Ni-enriched. The length of the Cr-Fe depleted zone was around $183 \mathrm{~nm}$. The elemental distributions in the IOZ were similar to those observed in the IOZ of LGB meaning that $\mathrm{Ni}, \mathrm{Cr}$, and Fe were all slightly depleted while the oxygen was enriched. In addition, Cr-rich and Ni-rich discrete regions introduced by the selective oxidation were also found. The situation in the narrow crack zone was different from that detected in the IOZ, with the presence of both the Cr-rich oxide and the Ni-rich metal distributed side by side. The evident separation of $\mathrm{Cr}$-rich oxides and $\mathrm{Ni}$-rich metal was also reported by Bertali et al. [13] and Langelier et al. [46] in Alloy 600 exposed to high temperature hydrogenated steam, which was believed to be grain boundary migration. The authors considered that the formation of the grain boundary migration was the result of different diffusion rate of $\mathrm{Cr}$ and $\mathrm{Ni}$.

To quantitatively understand the elemental distribution, a series of EELS line-scan were conducted. The 
EELS line-scan positions are presented in Fig. 7a and the corresponding line profiles are shown in Fig. 7c-g, respectively. Fig. 7c confirms a slight $\mathrm{Cr}$-Fe depletion and Ni-enrichment in the grain boundary far from the crack tip. A Ni-rich region was also observed just ahead of the IOZ tip (see Fig. 7d). Fig. 7e shows that the metallic density was lower in the IOZ-metal interfaces than in the IOZ. Fig. $7 \mathrm{f}$ and $7 \mathrm{~g}$ show the separation of a Ni-rich region and a Cr-rich region in the narrow crack zone. Oxygen was lower in the Ni-rich region while enriched in the Cr-rich region, which suggests the localized formation of $\mathrm{Cr}_{2} \mathrm{O}_{3}$. The elemental distributions across the wide crack zone were similar to that observed in the open crack zone of LGB, with a single layer of $\mathrm{Ni}\left(\mathrm{Fe}_{\mathrm{x}}, \mathrm{Cr}_{1-\mathrm{x}}\right)_{2} \mathrm{O}_{4}$ spinel on the crack flanks (see Fig. 7h).

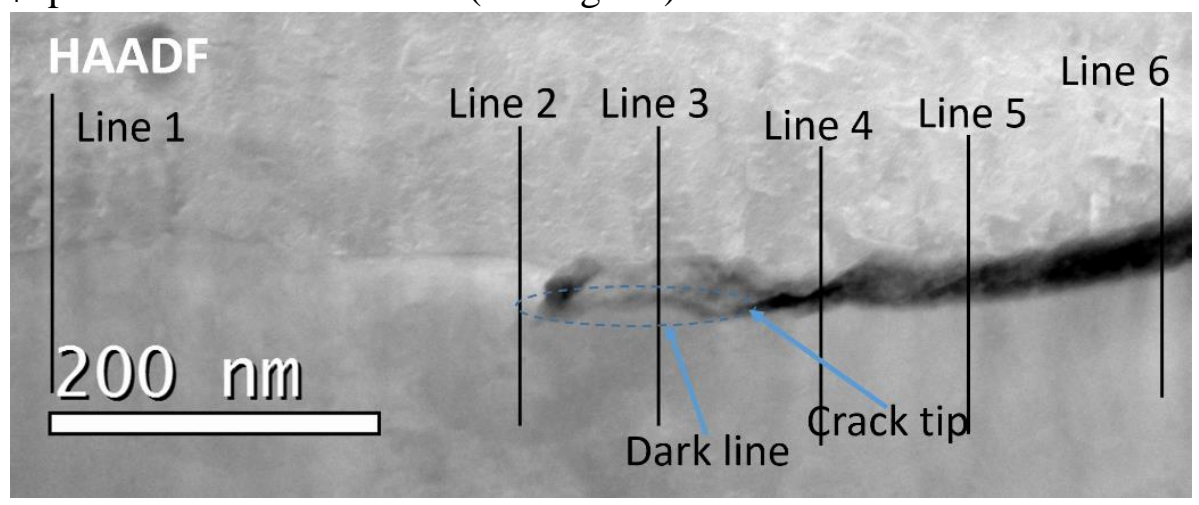

(a)

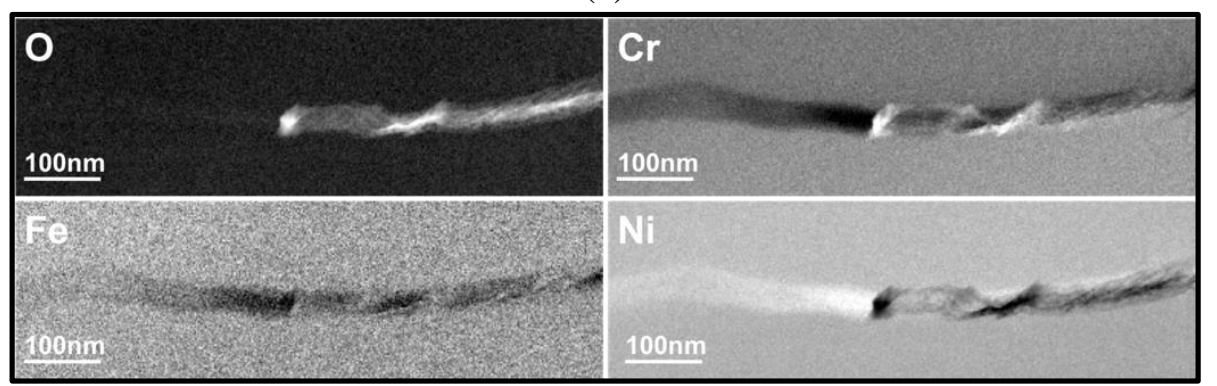

(b)

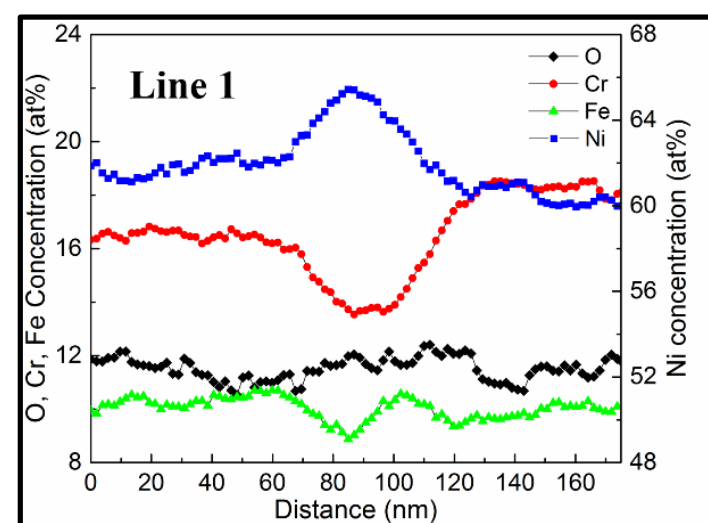

(c)

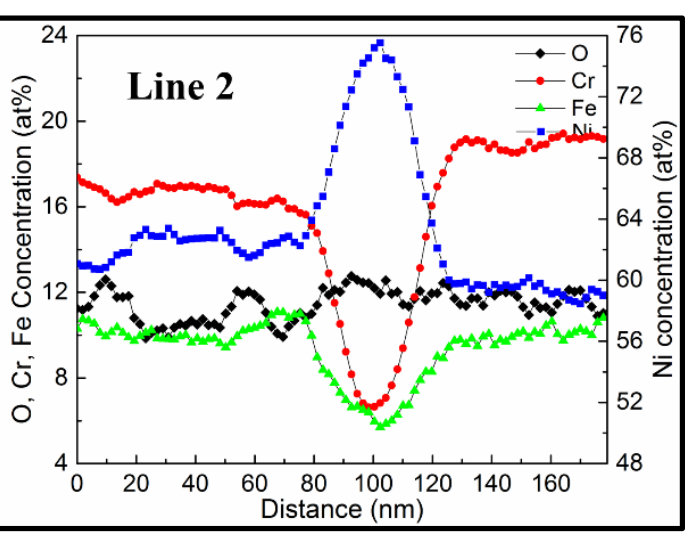

(d)

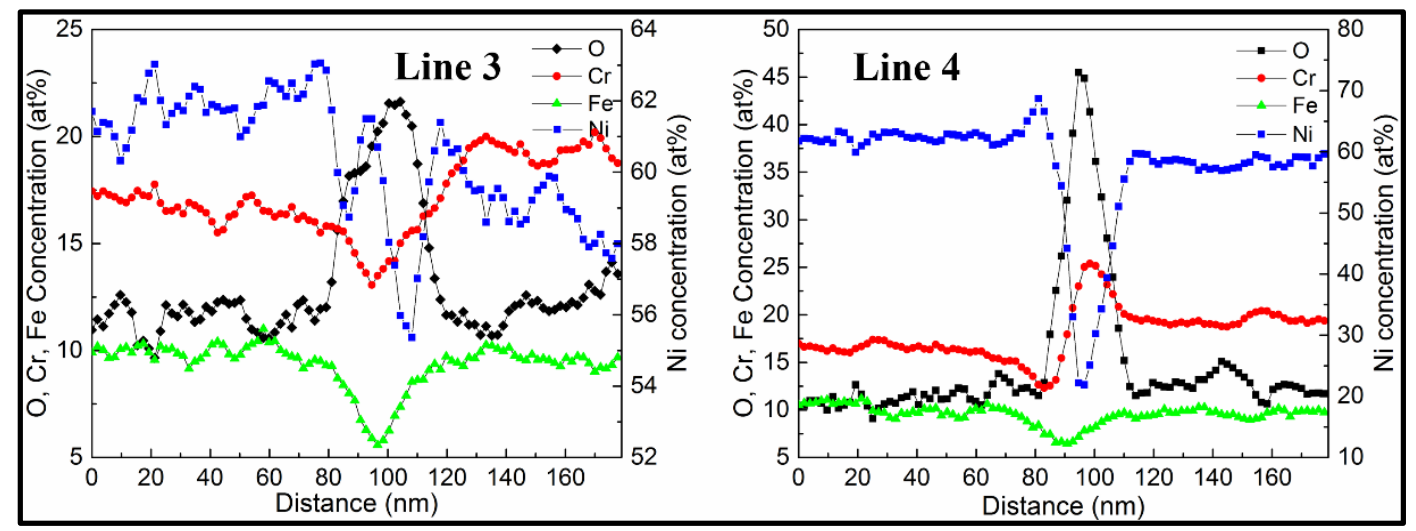




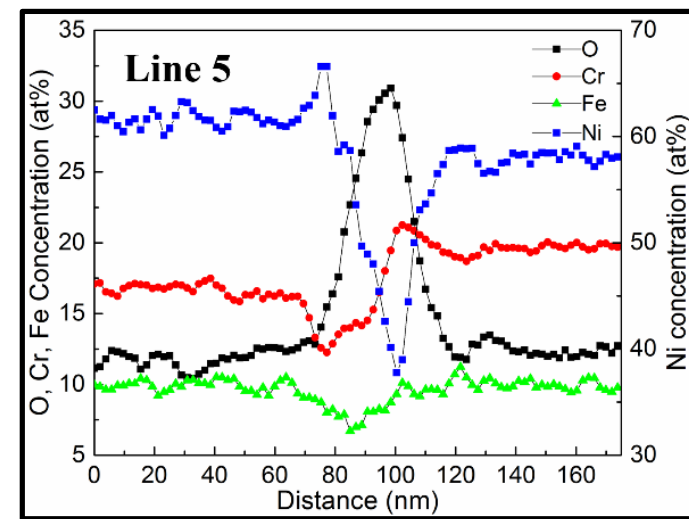

(g)

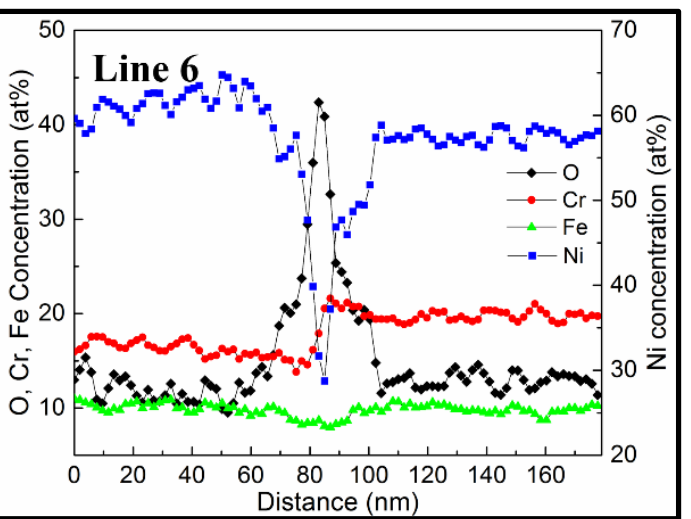

(h)

Fig. 7. (a) STEM-HAADF image of an active CLSB ( $\left.\sum 25 \mathrm{~b}\right)$ crack tip with indication of EELS line-scan locations; (b) EELS elemental $\mathrm{O} \mathrm{K}$ edge and $\mathrm{Cr} / \mathrm{Fe} / \mathrm{Ni}$ L edge maps (step size $=1.5 \mathrm{~nm}$ ) with relative error lower than 10\%; Composition line profiles obtained through EELS analysis performed at the grain boundary far from crack tip(c); just ahead of the leading edge of the IOZ (d); at the IOZ (e); at the tip of narrow crack zone (f); at the end of narrow crack zone (g); at the wide crack zone (h).

\subsubsection{SCC-attacked HGB $\left(\sum>29\right)$}

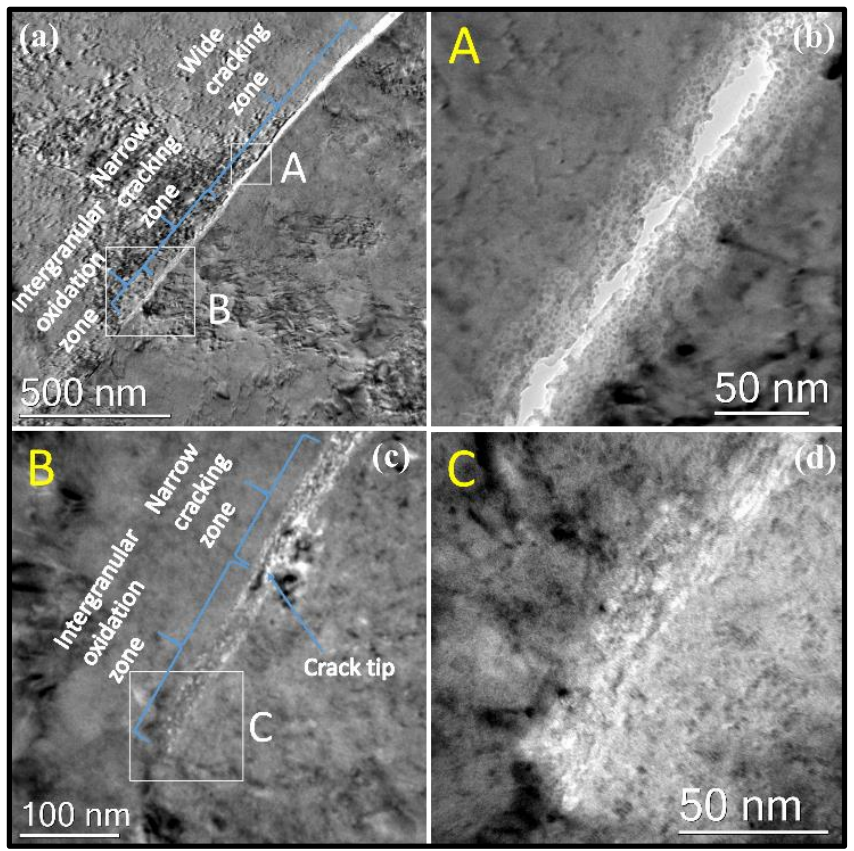

Fig. 8. (a) TEM bright field image of an active crack developing along a RHGB; (b) a magnified view of the rectangular area $\mathrm{A}$ in (a); (c) a magnified view of the rectangular area B in (a); (d) a magnified view of the rectangular area $\mathrm{C}$ in (c).

An overview of a HGB crack tip can be seen in Fig. 8a, with an uncracked IOZ, a narrow crack zone, and a wide crack zone. The characteristic feature associated with the SCC-attacked HGB was also the existence of a long and narrow IOZ. The structure in this zone was porous, and the total length of this zone was around $171 \mathrm{~nm}$, as shown in Fig. 8c. Average diameter of cavities in the IOZ was measured to be around $1.5 \mathrm{~nm}$. The study of the narrow crack zone reveals that the crack propagated along the IOZ-metal interface. Oxidation was observed on the crack flanks and the crack was not full of oxide, as shown in Fig. 8b. A higher magnification image was obtained in the vicinity of the IOZ tip (rectangular region C), further proving the existence of nano-pores, especially at the IOZ-metal interfaces. Average diameter of the pores in the IOZ was 
measured to be around $1.5 \mathrm{~nm}$.

A HAADF image (see Fig. 9a) around the IOZ tip was obtained. Similar to the CSLB $\left(\sum 25 b\right)$, the crack propagated along the IOZ-metal interface. To understand the elemental distribution, EELS mapping was conducted, as shown in Fig. 9b. Even though the step size for this EELS mapping was also $1.5 \mathrm{~nm}$, the changes in chemical composition around the grain boundary were not as obvious as those in the TEM samples of LGB and CSLB $\left(\sum 25 b\right)$. This is mainly due to the projection effect introduced by a more inclined grain boundary plane in the TEM sample (as a reminder, all samples were extracted in plan-view, so the GB angle cannot be controlled). However, since the sample thickness was only around $50 \mathrm{~nm}$, the typical features can still be distinguished. $\mathrm{Cr}$-Fe depletion and Ni-enrichment were detected at a significant distance ahead of the crack tip. The length of the $\mathrm{Cr}-\mathrm{Fe}$ depleted zone was measured to be around $256 \mathrm{~nm}$. In addition, both a Ni-rich zone and a Cr-rich oxide zone were observed ahead of and at the tip of the IOZ, respectively. The Cr-map in the Fig. 9b shows that the thickness of Cr-enriched oxide was not uniform. However, even though the thickness of the Cr-rich oxide film was very thin (around $10 \mathrm{~nm}$ ) it seems to be enough to slow down the oxygen diffusion, as shown in the O-map (see Figure 9b). The limited chemical resolution in these particular EELS maps might have prevented the observation of a Cr-rich oxide and Ni-rich discrete regions in the IOZ.

A series of EELS line-scans were also conducted to understand the chemistry distribution quantitatively. The EELS line-scan positions are presented in Fig. 9a, and the corresponding line profiles are shown in Fig. 9c-f, respectively. The slight $\mathrm{Cr}$ depletion at the grain boundary far from the crack tip (see Fig. 9c) and a Nirich zone ahead of the tip of the IOZ (see Fig. 9d) were further confirmed by the compositional profiles. The chemical distributions in the IOZ and the narrow crack zone confirmed that metallic elements were depleted and oxygen was enriched. Fig. 9e shows that the oxygen content in the IOZ-metal interfaces was higher than in the IOZ, indicating the interfaces were preferentially attacked by the oxygen diffusion into the grain boundary. This observation is consistent with the HAADF image shown in Fig. 9a where the interface regions were darker than the IOZ. Fig. 9f illustrates that content of oxygen was higher in the narrow crack zone than in the IOZ, which should be due to a longer exposure time and direct contact with water. Since the narrow crack zone suffered greater extent of oxidation, the atomic density was lower than in the IOZ, which agrees well with the image contrast in the Fig. 9a.

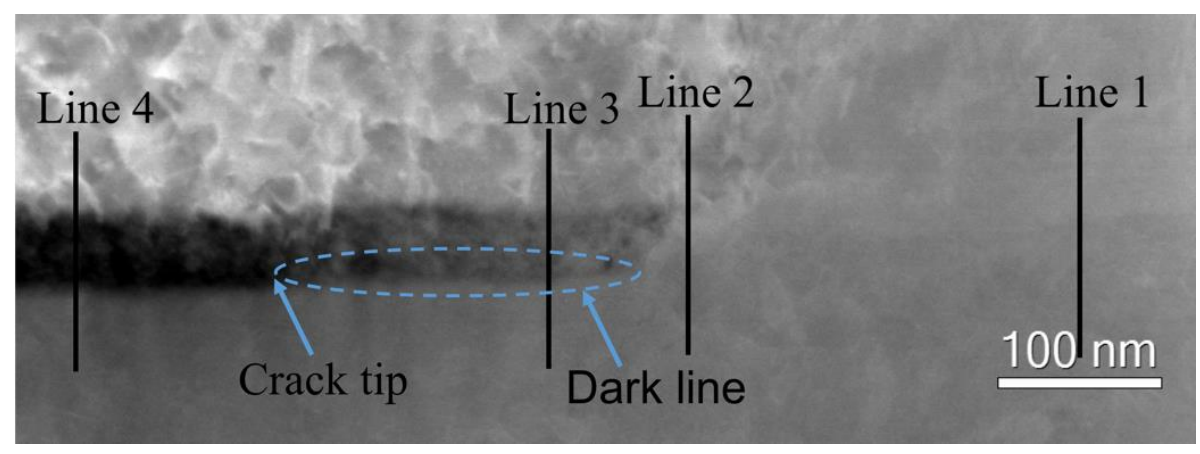

(a)

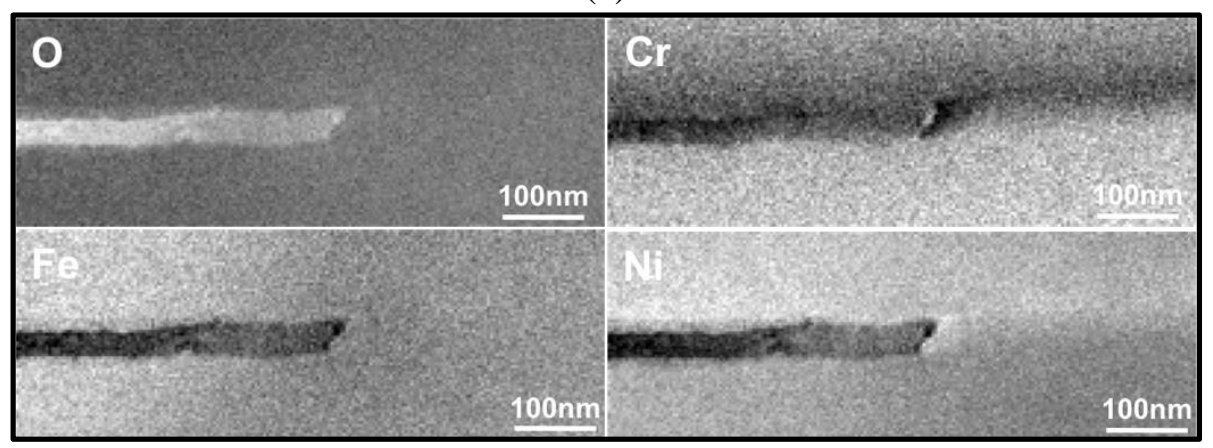

(b) 


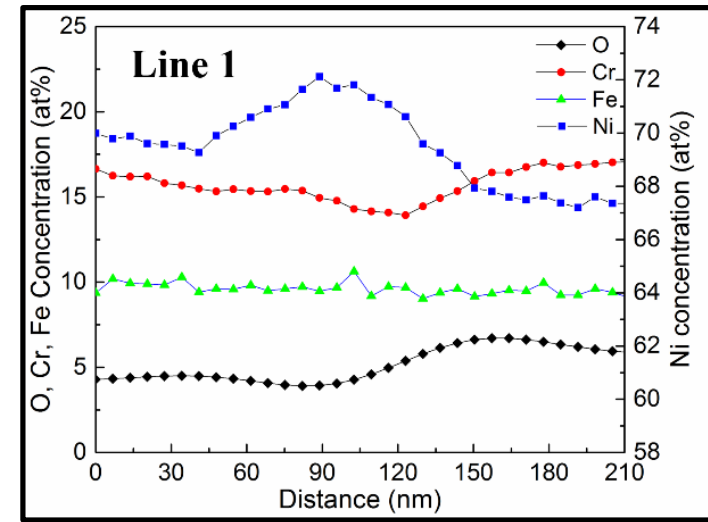

(c)

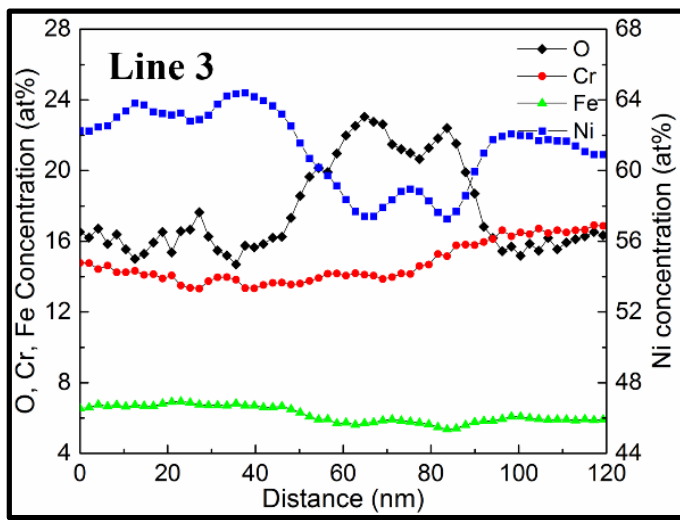

(e)

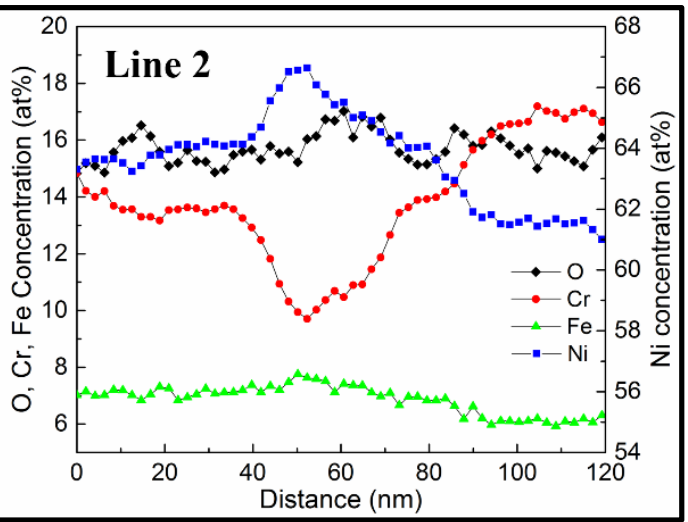

(d)

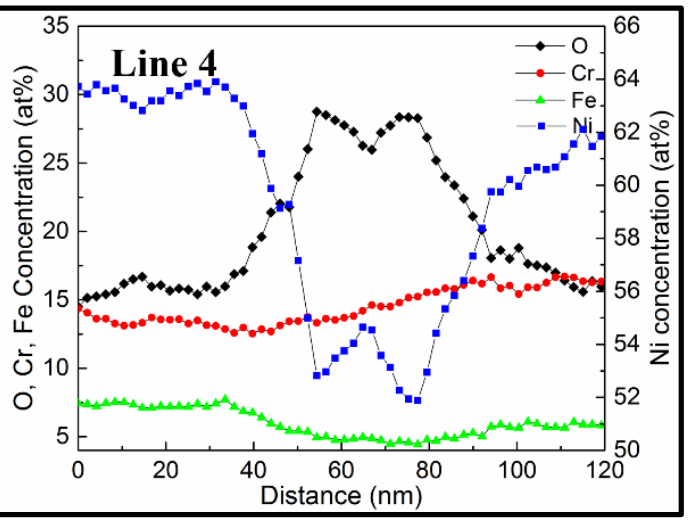

(f)

Fig. 9. STEM-HAADF image of an active HGB crack tip with indication of EELS line-scan locations; (b) EELS elemental $\mathrm{O} \mathrm{K}$ edge and $\mathrm{Cr} / \mathrm{Fe} / \mathrm{Ni}$ L edge maps (step size $=1.5 \mathrm{~nm}$ ) with relative error lower than $10 \%$; Composition line profiles obtained through EELS analysis performed at the grain boundary far from crack tip (c); just ahead of the leading edge of IOZ (d); at the IOZ (e); at the wide crack zone (f).

\subsection{TKD characterization}

Yield strength [45] and localized plastic deformation [31-35, 49] are known to affect the SCC susceptibility. Therefore, a mechanism controlled by the mechanical response to the internal stresses and externally applied loading during the SCC testing is worth considering. TKD was first utilized by Meisnar et al. $[22,27]$ in the study of SCC to characterize the localized deformation around crack tips on stainless steels. MO maps were calculated and used to describe the size and extent of localized deformation zone (LDZ) around crack tips. In the current study, all TEM samples containing crack tips were studied via TKD after the (S)TEM analysis. The step size was $10 \mathrm{~nm}$. The indexing rates of all TKD measurements were better than $90 \%$. The non-indexed pixels in all TKD maps were labeled black.

\subsubsection{SCC-attacked LGB $\left(\sum 1\right)$}

The high-resolution of TKD technique enabled the location of the grain boundary and crack in the TKD maps. Fig. 10a shows the image quality map. The relatively low image contrast around the crack tip indicated the existence of higher defect density in this region. The IPFZ map shows the presence of two grains with different crystallographic orientations, which appear in different colors in Fig. 10b. The colors are referred to the austenite orientation triangle, shown as an inset in the IPFZ map. Fig. 10c shows the average MO map where each pixel represented the MO value in this pixel with regard to the average MO value of all pixels in the same grain. A color temperature scale, ranging from blue (low) to red (high), was adopted to describe the different MO values. Regions with higher MO value appeared brighter (green, yellow, and red) than regions with low MO value (blue). It is clear that brighter colors appear in the left grain. This might be caused by the sample bending during the sample preparation but not by the external load during the SCC test, since the 
external load used in this study was not high enough to cause this high extent of deformation in the material. Furthermore, the thickness of samples used in this study was only around 50nm, which means it is possible that the internal stress accumulated during prior cold-work could lead to sample bending/buckling. The sample bending was indeed observed in some TEM samples during the thinning process with FIB. Further observation of Fig. 10c reveals a locally elevated lattice rotation adjacent to the crack tip. Similar phenomenon was also reported by Meisnar et al. [22, 27]. The authors believed that this localized lattice rotation was the results of the prior cold-work and later external-load. In addition, there was a portion of grain boundary region just ahead of the LDZ that was also not indexed. This region coincides with the IOZ observed in section 3.2, which consists of a mixture of oxides with a small grain size. Similar to references [22, 27], MO profiles were extracted from crack tip outwards into the matrix to measure the size of LDZ and the lattice rotation. Line positions are shown in Fig. 10c, and the corresponding MO line profiles are presented in Fig. 10d and 10e. To measure the lattice rotation caused by the localized deformation from the MO profiles, it is necessary to subtract the value caused by the sample bending. As shown in Fig. 11d, there are two slopes in this MO profile. The presence of the second slope indicates the existence of sample bending. Therefore, the lattice rotation measured from the first slope consisted of two parts: deformation induced lattice rotation and sample bending induced lattice rotation. If we assume that the sample bending in the direction of MO profile is uniform, we can calculate the lattice rotation caused by sample bending in the LDZ through the second slope and LDZ size. Details about the calculation method are presented in Fig. 10d and the results show that the size of LDZ in the left grain was $280 \mathrm{~nm}$, and the lattice rotations caused by the localized deformation and the sample bending are $2.4^{\circ}$ and $1.2^{\circ}$ (error $\sim 1.1^{\circ}$ ), respectively. Fig. 10e shows that there was almost no sample bending in the right grain. The LDZ size and the lattice rotation caused by localized deformation were $250 \mathrm{~nm}$ and $1.6^{\circ}$ (error $\sim 1.1^{\circ}$ ), respectively.

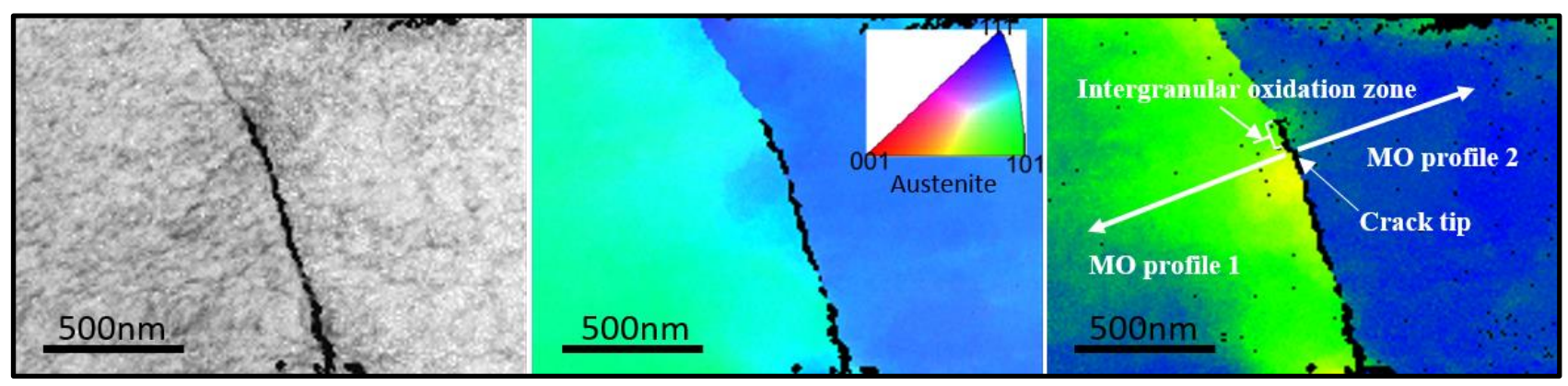

(a)

(b)

(c)
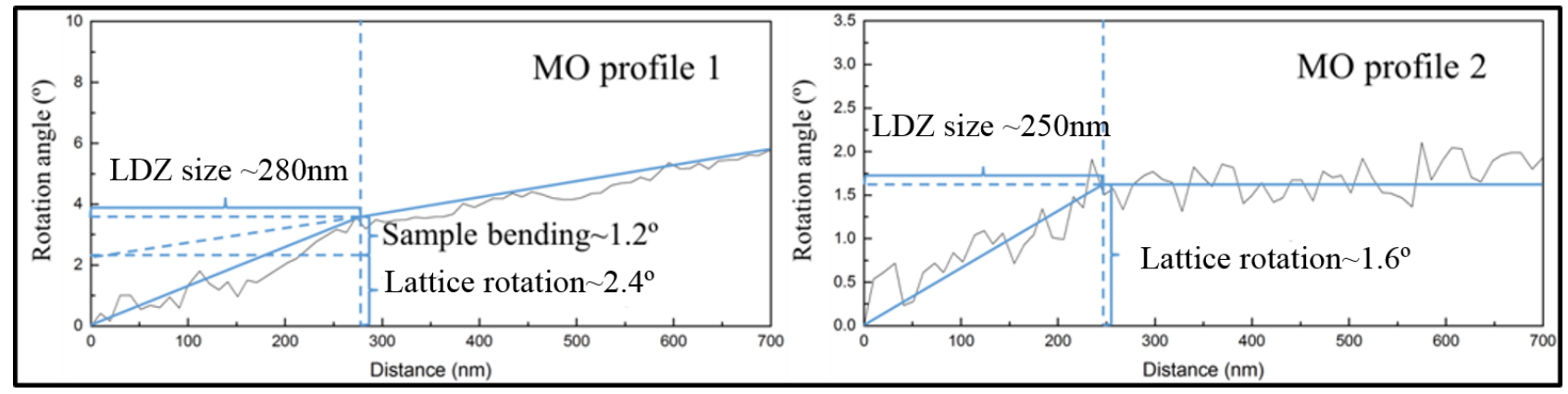

(d)

(e)

Fig. 10. TKD maps containing an active LGB crack tip (step size $=10 \mathrm{~nm}$ ): (a) image quality map; (b) IPFZ map; (c) average MO map with indication of MO line profile positions. (d) MO profile 1; (e) MO profile 2.

\subsubsection{SCC-attacked CSLB $\left(\sum 25 b\right)$}

The image quality map, IPFZ map, and average MO map containing an active CSLB $\left(\sum 25 \mathrm{~b}\right)$ crack tip are shown in Figs. 11a-c. An intergranular carbide was observed in this specimen. TKD diffraction patterns confirmed that the carbide was $\mathrm{Cr}_{7} \mathrm{C}_{3}$. The MO map revealed localized deformation around the carbide. This 
phenomenon has been observed in all other samples containing carbides at grain boundaries. In order to understand how the localized deformation was produced, TKD examination was also conducted on nonautoclaved cold-worked and non-cold-worked samples. The results show that the localized elevated deformation around the intergranular carbides was only found in the cold-worked sample (not shown). As a result, the localized deformation around the carbides can be explained due to the incompatible slip paths between the matrix and the carbide during the cold-work. MO profiles were extracted around the crack tip and the results are shown in Fig. $11 \mathrm{~d}$ and 11e. The size of the LDZ in the top grain was around $230 \mathrm{~nm}$ while the lattice rotations caused by the localized deformation and the sample bending were $3.8^{\circ}$ and $2.2^{\circ}$ (error $\sim 1.1^{\circ}$ ), respectively. The deformation around the crack tip in the bottom grain was much lower than in the top grain. The size of the LDZ was around $105 \mathrm{~nm}$ while the lattice rotation produced by the localized deformation was around $1.8^{\circ}$ (error $\sim 1.1^{\circ}$ ).

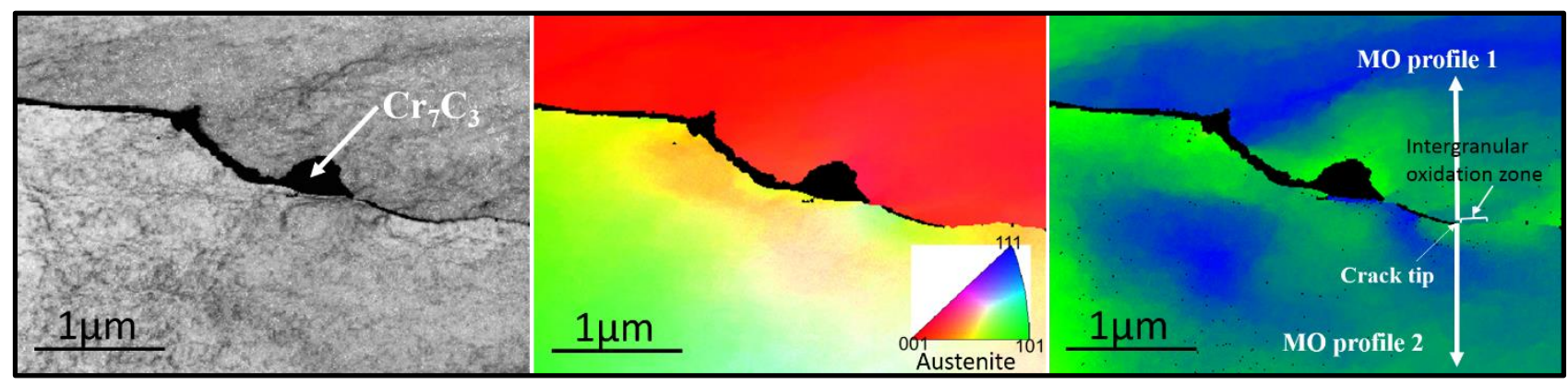

(a)

(b)

(c)

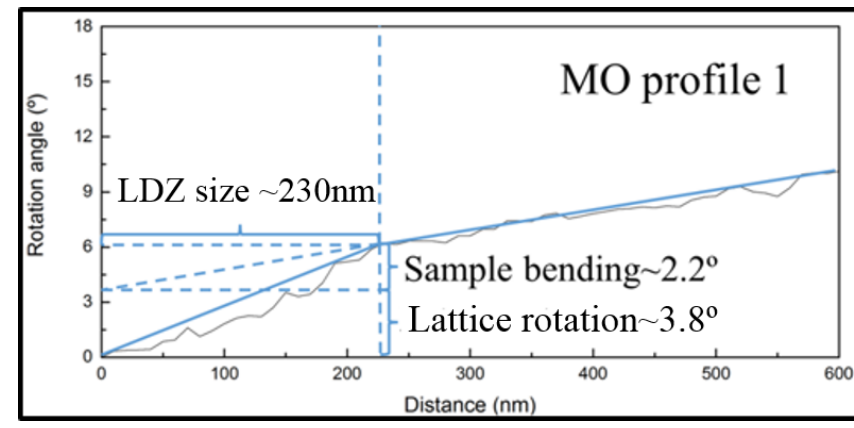

(d)

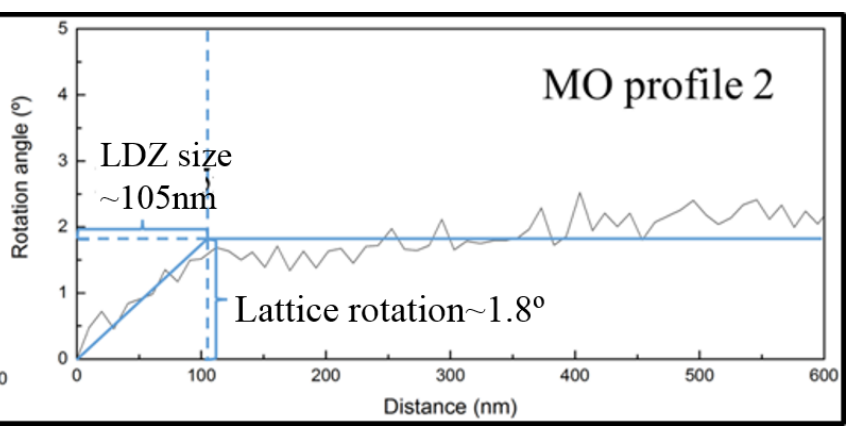

(e)

Fig. 11. TKD maps containing an active CSLB $\left(\sum 25 \mathrm{~b}\right)$ crack tip (step size $=10 \mathrm{~nm}$ ): (a) image quality map; (b) IPFZ map; (c) average MO map with indication of MO line profile positions. (d) MO profile 1; (e) MO profile 2.

\subsubsection{SCC-attacked HGB $\left(\sum>29\right)$}

Figs. 12a-c show the image quality map, IPFZ map, and average MO map of a region around an active HGB crack tip. A carbide was observed ahead of the crack tip, and TKD revealed it was also $\mathrm{Cr}_{7} \mathrm{C}_{3}$. Localized deformation also existed around the carbide. MO profiles were extracted to measure the deformation around the crack tip. The size of the LDZ in the top grain was around $105 \mathrm{~nm}$, while the angle of lattice rotation was around $1.6^{\circ}$ (error $\sim 1.2^{\circ}$ ). The extent of localized deformation around the crack tip of the bottom grain was higher than in the top one. The size of LDZ was around $180 \mathrm{~nm}$, while the lattice rotations induced by the localized deformation and the sample bending were $2.4^{\circ}$ and $0.9^{\circ}$ (error $\sim 1.2^{\circ}$ ), respectively.

In order to quantify the role of the mechanical deformation-based mechanism on SCC, the dislocation density in the LDZ must be known. The dislocation density can be calculated from TKD datasets, as shown in [27], but it is very time consuming. According to Ashby [34], matrix rotation gradients can be related linearly to dislocation densities. We refer to the localized matrix rotation gradient as deformation intensity, calculated as below:

Deformation intensity $=$ Lattice rotation $/ \mathrm{LDZ}$ size $\times 100$

We use this parameter to qualitatively estimate the linear dislocation density in the LDZ since these two 
parameters are highly correlated. More details can be found in [27]. According to this formula, the extents of localized deformation around the LGB, CSLB, and HGB crack tips were calculated to be $0.8 \pm 0.6,1.7 \pm 0.7$, and $1.4 \pm 0.8 \% \mathrm{~nm}$, respectively.

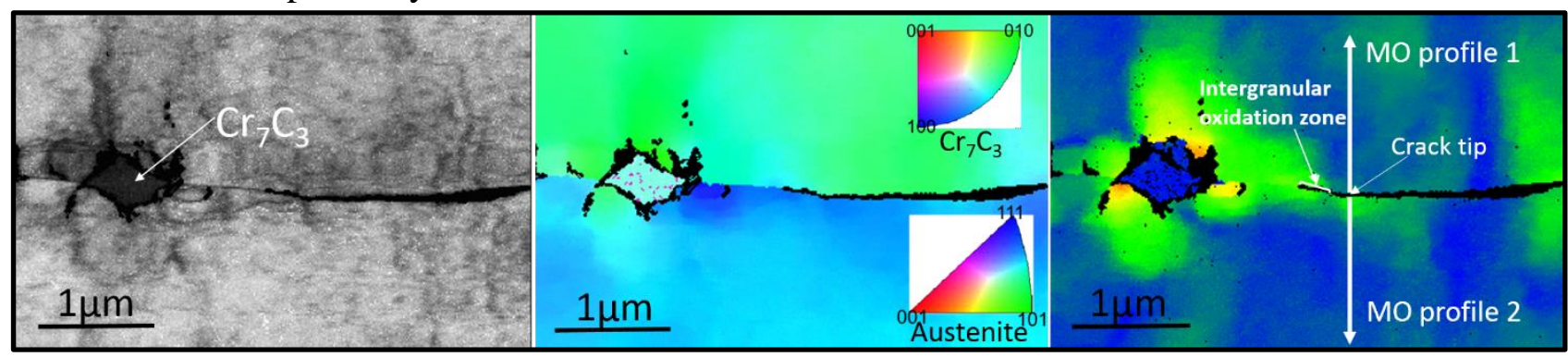

(a)

(b)

(c)

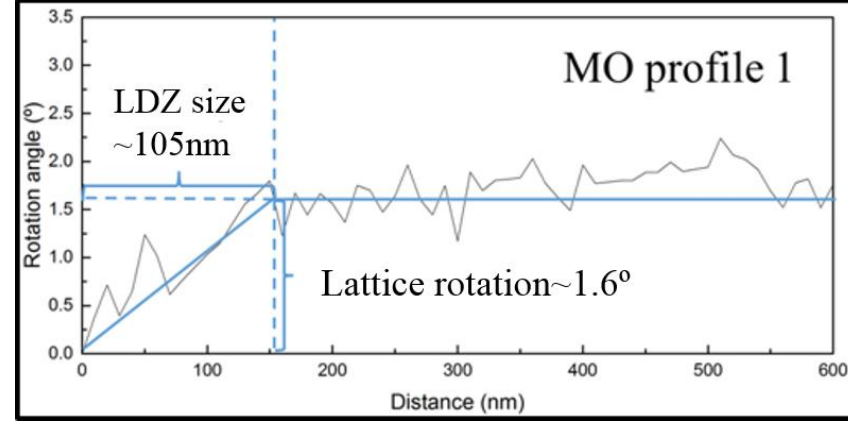

(d)

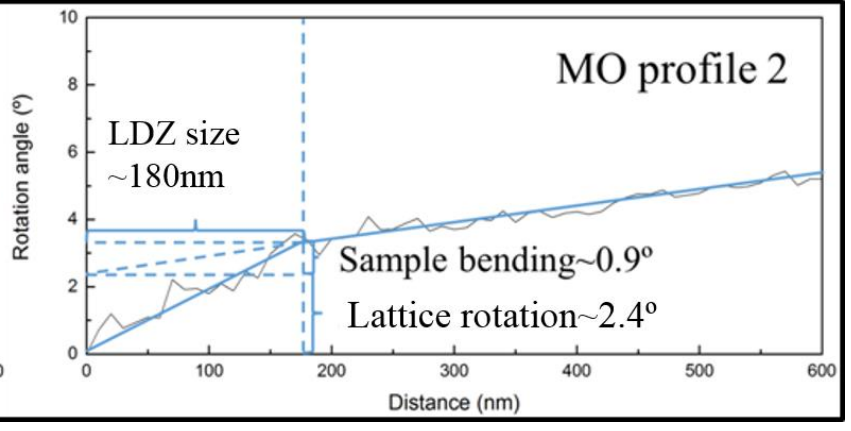

(e)

Fig. 12. TKD maps containing an active HGB crack tip (step size $=10 \mathrm{~nm}$ ): (a) image quality map; (b) IPFZ map; (c) average MO map with indication of MO line profile positions. (d) MO profile 1; (e) MO profile 2.

\section{Discussion}

Crack tips in three different kinds of susceptible grain boundaries have been comprehensively studied by (S)TEM and TKD in an attempt to reveal the underlying mechanisms controlling SCC in Alloy 600. The results have been presented in section 3 and some parameters obtained from this section are summarized in Table 2. The microstructure ahead of crack tips was found to be similar in all grain boundaries, with an uncracked and porous IOZ, followed by a Fe-Cr depleted region. As Table 2 reveals, the grain boundary type determines the extent of the intergranular diffusion ahead of the crack tip and the mechanical response around it. The presence of a brittle IOZ was a typical feature proving that the dominant mechanism could be the internal oxidation along the grain boundary $[6,8-14,51]$. According to the results reported by Wood et al. [53] and Whittle et al. [54], the internal oxidation could lead to the grain boundary embrittlement. In addition, Arioka et al. [58] and Meisnar et al. [27] found that the stress gradient in the LDZ can also lead to the grain boundary embrittlement through assisting the movement of vacancies towards the crack tip. As a result, understanding the precursors required for the SCC crack to propagate are deemed crucial. These precursors will be described in the next sections and are proposed to be: the creation of a Fe-Cr depleted region ahead of the crack tip, the formation of a brittle porous oxide in that region and the presence of localized deformation and applied stress to synergistically facilitate the previous two.

Table 2: IOZ length, Cr-Fe depletion length, LDZ size, and lattice rotation for the different samples. The LDZ size and lattice rotation are averaged.

\begin{tabular}{cccccc}
\hline Specimens & IOZ length $(\mathrm{nm})$ & Cr-Fe depletion length $(\mathrm{nm})$ & LDZ size $(\mathrm{nm})$ & Lattice rotation $\left(^{\circ}\right)$ & $\begin{array}{c}\text { Deformation intensity } \\
(\% / \mathrm{nm} \times 100)\end{array}$ \\
\hline LGB $\left(\sum=1\right)$ & 91 & 95 & 265 & $2 \pm 1.1$ & $0.8 \pm 0.6$ \\
CSLB $\left(\sum 25 \mathrm{~b}\right)$ & 150 & 183 & 168 & $2.8 \pm 1.1$ & $1.7 \pm 0.7$
\end{tabular}




\subsection{The influence of intergranular internal oxidation on SCC}

According to the results acquired in this work and elsewhere [8-11], intergranular internal oxidation plays an important role in the SCC of Alloy 600. As a characteristic feature of intergranular internal oxidation, the IOZ has been observed ahead of all the crack tips in this study, and was believed to be responsible for grain boundary embrittlement. Therefore, to understand the influence of intergranular internal oxidation on SCC, the first question is how the IOZ formed ahead of crack tips. Based on the results presented in section 3.2, since the $\mathrm{Cr}$ content at the original grain boundary was very low ( 14 in at\%), especially at those grain boundaries with carbides, the formation of a compact and continuous Cr-rich oxide film was very slow and difficult. As a result, a IOZ formed ahead of crack tips through the diffusion of oxygen along the grain boundary (see Fig. 5b, 7b, and 9b) before a more protective Cr-rich oxide film had time to develop. This $\mathrm{Cr}$ rich oxide was identified as $\mathrm{Cr}_{2} \mathrm{O}_{3}$ with thicknesses ranging from 10 to $30 \mathrm{~nm}$. Once this $\mathrm{Cr}$-rich oxide film developed at the grain boundary, the diffusion rate of oxygen can be effectively decreased (see Fig. 5b, 7b, and 9b). The Cr-rich oxide film has been reported in Alloy 600 elsewhere, but it was located at crack tip not at the tip of the IOZ [8-11]. According to the discussion above, the relatively low $\mathrm{Cr}$ content in the grain boundary of Alloy 600 could explain the formation of IOZ. This hypothesis can be further supported by the fact that Alloy 690, with higher Cr content, is more resistant to SCC than Alloy 600 [55, 56]. The high Cr content in Alloy 690 enables the fast formation of a compact Cr-rich oxide film and prevents the formation of the IOZ.

The next question to answer is why the presence of an IOZ is detrimental to the SCC of Alloy 600. According to the results obtained in section 3.2, this is because the oxidation in the IOZ was not uniform but selective when it was exposed to primary water of PWR within the dissolved hydrogen content at the Ni-stable region (see Fig. 5, 7, and 9). Once the grain boundary is selectively oxidized, the strength of the oxidized grain boundary is then significantly weakened, leading to grain boundary embrittlement [12, 48]. The brittle oxidized grain boundary can then be fractured by stresses of a few hundred MPa $[12,48]$. Based on the results obtained in this work and reported by other researchers [8-11, 57], the strength of grain boundaries can be reduced by the internal oxidation through two ways. The first one is that the oxygen selectively reacts with the metallic $\mathrm{Cr}$ and $\mathrm{Fe}$ to form Cr-rich oxides while metallic $\mathrm{Ni}$ is pushed to the surrounding environment, leading to the precipitation of the phases of Cr-rich oxide and Ni-rich metal in the IOZ (see Fig. 5b, 7b, and 9b). Since there is no orientation relationship between these new phases and their surrounding metal, the cohesion between them is much lower than the original metallic bonding. The second one is the formation of pores and voids in the oxides and at the interface between the oxide and matrix. The existence of pores and voids has been verified by the Fresnel contrast images, as shown in Fig. 4-8. It is worth noting that the crack did not propagate into the IOZ, but along the IOZ-metal interface. A similar phenomenon has been reported by Dugdale et al. [12]. The authors found a layer of Fe-rich spinel oxide with lower density at the IOZ-metal interface. However, even though there was also a lower density region at the IOZ-metal interface in this study, it was not a Fe-rich oxide but a Ni-depleted oxide. This localized Ni-depleted region had been oxidized which lead to the migration of Ni from the IOZ-metal interface outward into the IOZ. This hypothesis has been verified by the EELS line-scan results showing that the content of $\mathrm{Ni}$ at the IOZ-metal interfaces is much lower than in the central part of the IOZ (see Fig. 5e, 7e, and 9e). This might be the reason why the crack preferentially propagates along this interface. In addition, the TEM Fresnel contrast images show that there is a higher density of pores at the IOZ-metal interfaces, which might be another possible reason for this preferential cracking (see Fig. 4a, 6a, and 8d).

4.2 The influence of localized deformation around crack tips on SCC

In a recent study on SCC initiation of carbon steels, a possible connection between the formation of vacancies in grain boundaries ahead of crack tips and SCC growth was proposed by Arioka et al. [58]. The 
authors believed that the stress gradient ahead of crack tips can lead to the movement of vacancies toward the crack tips, and impede the movement of dislocations, which would concentrate in that region. The defects in the crack tip region can then not only enhance the intergranular oxidation, but also promote the structural embrittlement. A LDZ (see Fig. 10-12) caused by the internal stress and external-load has been observed around the crack tips by TKD in this study, which is consistent to other reports $[22,27]$. The authors found that the CGR of SCC increased with the extent of localized deformation. In order to understand the roles of the stress (internal and induced) and localized deformation, the extent of localized deformation around the crack tip was calculated for each type of grain boundary. The results are summarized in Table 2, and are similar to those observed in the $316 \mathrm{SS}$ exposed to primary water of PWR at $360^{\circ} \mathrm{C}$, but smaller than $316 \mathrm{SS}$ at $320^{\circ} \mathrm{C}$ [27]. The reason behind the different mechanical-response of Alloy 600 and $316 \mathrm{SS}$ at $320^{\circ} \mathrm{C}$ is still unclear, although the key might be in their different stacking fault energies and their abilities to dissociate dislocations when under stress.

In the study of 316SS, the CGR was significantly enhanced by the extent of localized deformation around crack tips [27], which can be related to the localized dislocation density. Although the extent of localized deformation in the Alloy 600 at $320^{\circ} \mathrm{C}$ was much lower than what was reported for $316 \mathrm{SS}$ at the same temperature [27], the role of localized deformation on SCC of Alloy 600 should not be neglected. According to Lim et al. [11], the SCC susceptibility of Alloy 600 without cold-work is lower than what was observed in this work. Since the experimental conditions in these two works are identical, the cold-work induced deformation should have played an important role in accelerating the CGR of SCC. Lozano-Perez et al. [59] reported that cold-work can remarkably increase the internal oxidation by assisting the diffusion of metallic and nonmetallic elements in the regions with higher defect density. Similar results have also been reported by Terachi et al. [60]. These authors believed that the defects caused by plastic deformation can act as fast diffusion paths, accelerating the oxidation and embrittlement of the grain boundary. Although the extent of localized deformation around the crack tip of Alloy 600 was lower than in 316SS, the relative small stress gradient can still assist the movement of a large number of vacancies toward the crack tip due to the high defect density in the cold-worked material. As a result, the acceleration effect of cold-work and external load induced localized deformation on the SCC propagation should not be neglected.

4.3 The influence of grain boundary character on SCC

It is well known that SCC susceptibility is affected by the type of grain boundary [6, 8, 9, 19-21]. The LGBs $\left(\sum=1\right)$ and CSLBs $\sum\left(3 \leq \sum \leq 29\right)$ with low values of the reciprocal density of coincident sites are usually treated as "special" grain boundaries which are considered to have higher resistance to degradation, whereas, the CSL boundaries with values greater than $\sum 29$ are believed to exhibit lower resistance [19, 21]. According to the results obtained in this study, only $\sum 3$ boundaries seem to be immune to SCC. As discussed in section 3.2, the length of IOZ ahead of crack tip and the Cr-Fe depleted zone ahead of Cr-rich oxide have been used to describe the SCC susceptibility of a specific grain boundary. Considering the errors caused by the measurements and potentially different exposure times, it is still reasonable to conclude that the SCC susceptibility of the HGB was similar to the CSLB $\left(\sum 25 b\right)$ but higher than the LGB, as shown in Table 2. Both the LGB and CSLB $\left(\sum 25 b\right)$ in this study have suffered severe oxidation, indicating they are not "special" in resisting SCC. This conclusion diverges from the results reported by Was et al. [20]. The authors considered that the LGB is immune to SCC while the CSLB has much higher resistance to SCC than HGB. This discrepancy might come from the different levels of cold-work in the material used. As discussed in section 4.2, the cold-work induced defects in the material can significantly increase the SCC susceptibility. As a result, the effect of grain boundary character on the SCC resistance can be changed by the cold-work. A similar result was found for 304 steel [59]. It is necessary to mention that due to limited number of crack tips examined, the comparison between the SCC susceptibility of different types of grain boundary should be taken as qualitative at this stage.

4.4 Current understanding of the internal oxidation mechanism 


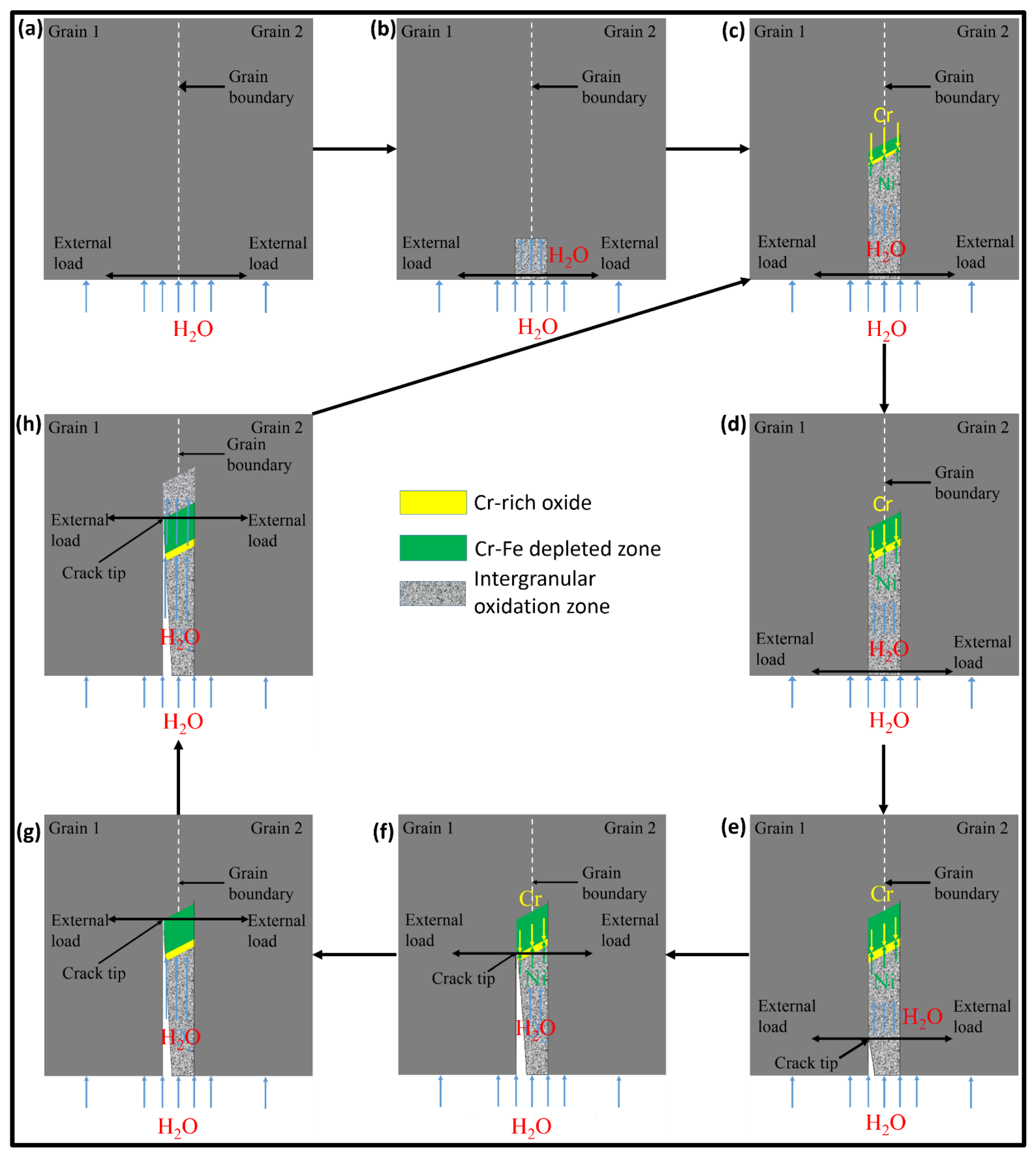




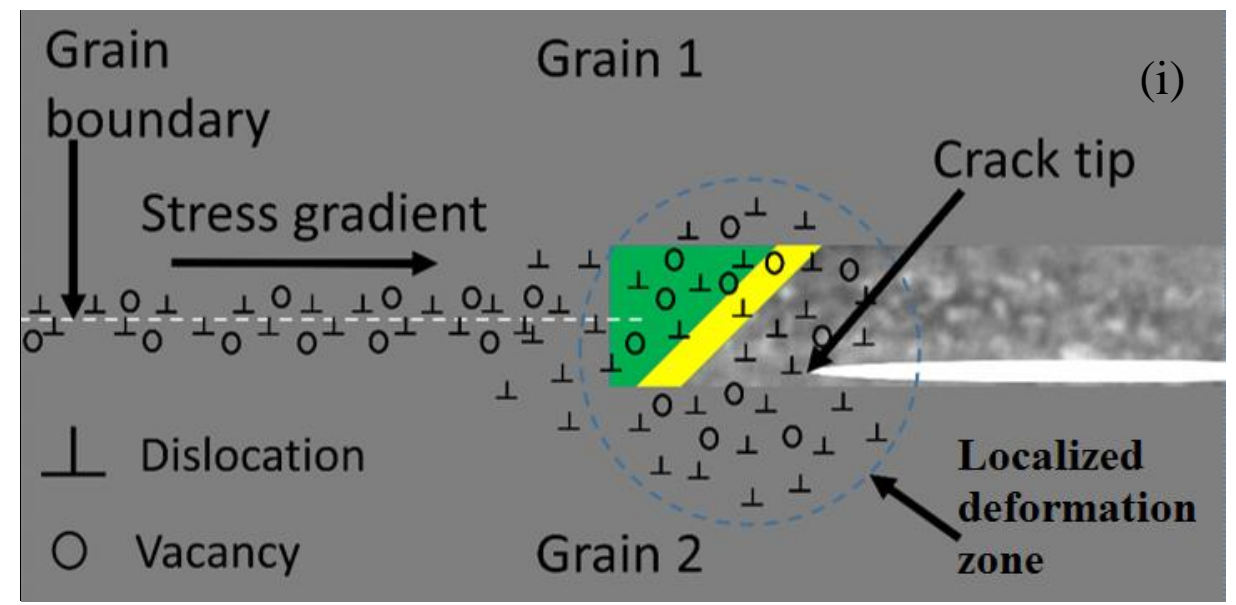

Fig. 13. Schematic illustration of (a-g) the processes of internal oxidation activated SCC propagation and (i) stress gradient induced vacancy movement.

Based on the experimental evidence found in this study, a detailed description of SCC propagation in Alloy 600 and the required precursors are presented in Fig. 13. PWR primary water has little or no oxygen in solution. We can assume that water molecules can reach into the material if there are wide enough defects (e.g. dislocations or pores, see Fig. 4e). At some point, water dissociation will occur and oxygen (or $\mathrm{OH}-$ ) will react with the metal atoms. In our proposed model, when a stressed grain boundary is exposed to the PWR primary water, water can diffuse through the microstructural defects (see Fig. 13a and b). The diffusion length of water along the grain boundary is expected to be greater than through the grain because the higher content of defects and the intergranular $\mathrm{Cr}$-depletion caused by the precipitation of $\mathrm{Cr}_{7} \mathrm{C}_{3}$. Once the water diffuses into the grain boundary, the material will suffer selective oxidation, because the dissolved hydrogen content in the water was at the Ni-stable zone. This leads to the formation of an IOZ along the grain boundary (see Fig. 13b). Since the $\mathrm{Cr}$ content in the grain boundary is lower, especially in the vicinity of carbides, the formation of a continuous layer of protective Cr-rich oxide film is unlikely. Therefore, the length of intergranular oxide will keep increasing until it can passivate. The $\mathrm{Cr}$ and the $\mathrm{Fe}$ in the $\mathrm{Cr}$-rich oxide film is mainly from the grain boundary ahead, resulting in $\mathrm{Fe}$ - and $\mathrm{Cr}$-depletion. At the same time, the $\mathrm{Ni}$ in the $\mathrm{IOZ}$ is expelled and accumulates ahead of the IOZ (see Fig. 13c and 13d). The structure of the Cr-rich oxide at the tip of IOZ becomes more compact with time. The structure of the IOZ becomes more porous and brittle, especially at the IOZ-metal interfaces. Once the external-load is greater than the strength of the IOZ-metal interface, cracking starts to occur along the IOZ-metal interface (see Fig. 13e). Although the presence of this newly developed crack can enable the diffusion of water into a deeper region, the $\mathrm{Cr}$-rich oxide film can effectively prevent this process. When the crack propagates further into the Cr-rich oxide film (see Fig. 13f), the water will start to diffuse into the Fe-Cr-depleted zone (Fig. 13g) and the cycle starts again (Fig. 13h). The faster crack growth rate along $\mathrm{Cr}$-depleted grain boundaries can also be indirectly proven by the fact that all cracks studied stopped at the stage illustrated in Fig. 13e when the sample was taken out from autoclave.

As discussed in section 4.2, the internal stress and external-load, could accumulate dislocations around crack tips, resulting in the formation of a stress gradient. The stress gradient could attract vacancies which then accelerate the intergranular oxidation and embrittlement and promote the formation of pores. A schematic illustration is presented in Fig. 13i.

It is worth noting that although the influence of intergranular internal oxidation and localized deformation on the SCC of Alloy 600 have been separately discussed in this work, these two factors interact synergistically. For example, the localized deformation could lead to the accumulation of defects around crack tips, which could not only cause grain boundary embrittlement but also accelerate the intergranular oxidation. In addition, the internal oxidation of the grain boundary ahead of crack tip could not only weaken the grain boundary strength ahead of crack tip but also increase the stress concentration.

\section{Conclusions}


Three active SCC crack tips on different types of grain boundary have been investigated by (S)TEM and TKD. The experimental results obtained in this work lead to the conclusion that the dominant mechanism on SCC propagation is intergranular internal oxidation. The grain boundaries (LGB and CSLB) with lower grain boundary energies also exhibited high SCC susceptibility due to prior cold-work and only the $\sum 3$ grain boundaries seem immune to SCC. The structure of an oxidized grain boundary is porous and brittle due to the selective oxidation and the deformation-induced defect accumulation, while the crack prefers to propagate along the IOZ-metal interface rather than through the IOZ. Although the Cr content is very low in this material, it is still enough to form discrete $\mathrm{Cr}_{2} \mathrm{O}_{3}$. However, the location of this Cr-rich oxide is not at the crack tips, but mostly at the leading edge of the IOZ. The extent of localized deformation around the different crack tips is similar but generally lower than that observed in 316SS at the same temperature. The major precursors contributing to the SCC crack propagation are the intergranular Cr depletion, the formation of a porous oxide, the prior cold-work and external-load induced localized deformation around the crack tips. The CGR along different types of grain boundaries in Alloy 600 is likely to depend on their ability to transfer slips from one grain to the other (and therefore accumulate defects and stress).

\section{Acknowledgements}

The authors would like to thank INSS (Japan) for providing the sample used in this study and for useful discussions. Zhao Shen is also grateful to China Scholarship Council for providing financial support. The EPSRC (EP/K040375/1 and EP/N010868/1) is acknowledged for funding the 'South of England Analytical Electron Microscope' and the FIB/SEM used in this research.

\section{References}

[1] IAEA: Ref. Data Ser. No.2, 2015, pp. 10-11.

[2] H. Coriou, L. Crall, Y. L. Gall, S. Vettier, 3rd Metallurgy Conf. on Corrosion, Saclay (Amsterdam, The Netherlands: North Holland Publishing Co., 1959), 1960, pp. 161-169.

[3] W. Bamford, J. Hall, "Cracking of alloy 600 nozzles and welds in PWRs: review of cracking events and repair service experience.", in: Proceedings of the 12th Int'1 Conf. on Environmental Degradation of Materials in Nuclear Power Systems - Water Reactor, Salt Lake City, UT, 2005, p. 959.

[4] P.L. Andresen, M.M. Morra. Stress corrosion cracking of stainless steels and nickel alloys in hightemperature water. Corrosion, 64 (2008): 15-29.

[5] P.L. Andresen, J. Hickling, A. Ahluwalia, J. Wilson. Effects of hydrogen on stress corrosion crack growth rate of nickel alloys in high-temperature water. Corrosion, 64(2008): 707-720.

[6] L.E. Thomas, S.M. Bruemmer. High-resolution characterization of intergranular attack and stress corrosion cracking of Alloy 600 in high-temperature primary water. Corrosion, 56(2000): 572-587.

[7] V.Y. Gertsman, S.M. Bruemmer. Study of grain boundary character along intergranular stress corrosion crack paths in austenitic alloys. Acta Materialia, 49(2001):1589-1598.

[8] S.M. Bruemmer, L.E. Thomas. High-resolution analytical electron microscopy characterization of corrosion and cracking at buried interfaces. Surface and interface analysis, 31(2001): 571-581.

[9] S. Lozano-Perez, J. M. Titchmarsh. TEM investigations of intergranular stress corrosion cracking in austenitic alloys in PWR environmental conditions. Materials at high temperatures, 20(2003): 573-579.

[10] M. Sennour, P. Laghoutaris, C. Guerre, R. Molins. Advanced TEM characterization of stress corrosion cracking of Alloy 600 in pressurized water reactor primary water environment. Journal of Nuclear Materials, 393(2009): 254-266.

[11] Y.S. Lim, H.P. Kim, S.S. Hwang. Microstructural characterization on intergranular stress corrosion cracking of Alloy 600 in PWR primary water environment. Journal of Nuclear Materials, 440(2013): 46-54. 
[12] H. Dugdale, D.E. Armstrong, E. Tarleton, S.G. Roberts, S. Lozano-Perez. How oxidized grain boundaries fail. Acta Materialia, 61(2013): 4707-4713.

[13] G. Bertali, F. Scenini, M. G. Burke. Advanced microstructural characterization of the intergranular oxidation of Alloy 600. Corrosion Science, 100 (2015): 474-483.

[14] Y.S. Lim, S.W. Kim, S.S. Hwang, H.P. Kim, C. Jang. Intergranular oxidation of Ni-based Alloy 600 in a simulated PWR primary water environment. Corrosion Science, 108(2016): 125-133.

[15] G. Bertali, F. Scenini, M. G. Burke. The effect of residual stress on the Preferential Intergranular Oxidation of Alloy 600. Corrosion Science, 111(2016): 494-507.

[16] B. Langelier, S. Y. Persaud, R. C. Newman, G. A. Botton. An atom probe tomography study of internal oxidation processes in Alloy 600. Acta Materialia, 109 (2016): 55-68.

[17] F.O.M. Gaslain, H.T. Le, C. Duhamel, C. Guerre, P. Laghoutaris, 2016. The role of intergranular chromium carbides on intergranular oxidation of nickel based alloys in pressurized water reactors primary water. In IOP Conference Series: Materials Science and Engineering (Vol. 109, No. 1, p. 012004). IOP Publishing.

[18] V. Randle. The Measurement of Grain Boundary Geometry, Institute of Physics Pub, Bristol (1993).

[19] A. Stratulat, J.A. Duff, T.J. Marrow. Grain boundary structure and intergranular stress corrosion crack initiation in high temperature water of a thermally sensitised austenitic stainless steel, observed in situ. Corrosion Science, 8(2014): 428-435.

[20] D.C. Crawford, G.S. Was. The role of grain boundary misorientation in intergranular cracking of Ni16Cr-9Fe in $360^{\circ} \mathrm{C}$ Argon and high-purity water. Metallurgical Transactions A, 23(1992): 1195-1206.

[21] G. Palumbo, E. M. Lehockey, P. Lin. Applications for grain boundary engineered materials. JOM, 50(1998): 40-43.

[22] M. Meisnar, A. Vilalta-Clemente, A. Gholinia, M. Moody, A.J. Wilkinson, N. Huin, S. Lozano-Perez. Using transmission Kikuchi diffraction to study intergranular stress corrosion cracking in type 316 stainless steels. Micron, 75(2015): 1-10.

[23] D.K. Schreiber, M.J. Olszta, S.M. Bruemmer. Grain boundary depletion and migration during selective oxidation of $\mathrm{Cr}$ in a $\mathrm{Ni}-5 \mathrm{Cr}$ binary alloy exposed to high-temperature hydrogenated water. Scripta Materialia, 89(2014): 41-44.

[24] S.I. Baik, M.J. Olszta, S.M. Bruemmer, D.N. Seidman. Grain-boundary structure and segregation behavior in a nickel-base stainless alloy. Scripta Materialia, 66(2012): 809-812.

[25] S. M. Bruemmer, M. J. Olszta, M. B. Toloczko, L. E. Thomas. Linking grain boundary microstructure to stress corrosion cracking of cold-rolled alloy 690 in pressurized water reactor primary water. Corrosion, 69 (2012): 953-963.

[26] M. Meisnar, M. Moody, S. Lozano-Perez. Atom probe tomography of stress corrosion crack tips in SUS316 stainless steels. Corrosion Science, 98(2015): 661-671.

[27] M. Meisnar, A. Vilalta-Clemente, M. Moody, K. Arioka, S. Lozano-Perez. A mechanistic study of the temperature dependence of the stress corrosion crack growth rate in SUS316 stainless steels exposed to PWR primary water. Acta Materialia, 114 (2016): 15-24.

[28] J. Hou, Q. J. Peng, Z. P. Lu, T. Shoji, J. Q. Wang, E-H. Han, W. Ke. Effects of cold working degrees on grain boundary characters and strain concentration at grain boundaries in Alloy 600. Corrosion Science, 53 (2011): 1137-1142.

[29] Z. Lu, T. Shoji, S. Yamazaki, K. Ogawa. Characterization of microstructure, localized deformation and microchemistry in Alloy 600 heat-affected zone and stress corrosion cracking in high temperature water. Corrosion Science, 58(2012): 211-228.

[30] A. King, G. Johnson, D. Engelberg, W. Ludwig, J. Marrow. Observations of intergranular stress corrosion cracking in a grain-mapped polycrystal. Science, 321(2008): 382-385.

[31] E. A. West, G. S. Was. A model for the normal stress dependence of intergranular cracking of irradiated 
316L stainless steel in supercritical water. Journal of Nuclear Materials, 2 (2011): 142-152.

[32] M.D. McMurtrey, G.S. Was, L. Patrick, D. Farkas. Relationship between localized strain and irradiation assisted stress corrosion cracking in an austenitic alloy. Materials Science and Engineering: A, 528(2011): 3730-3740.

[33] E.A. West, M.D. McMurtrey, Z. Jiao, G.S. Was. Role of localized deformation in irradiation-assisted stress corrosion cracking initiation. Metallurgical and Materials Transactions A, 43(2012): 136-146.

[34] M.F. Ashby. The deformation of plastically non-homogeneous materials. Philosophical Magazine, 21(1970): 399-424.

[35] M. D. McMurtrey, G. S. Was, B. Cui, I. Robertson, L. Smith, D. Farkas. Strain localization at dislocation channel-grain boundary intersections in irradiated stainless steel. International Journal of Plasticity, 56 (2014): 219-231.

[36] R.R. Keller, R.H. Geiss. Transmission EBSD from $10 \mathrm{~nm}$ domains in a scanning electron microscope. Journal of Microscopy, 245(2012): 245-251.

[37] S. Suzuki. Features of transmission EBSD and its application. JOM, 65(2013): 1254-1263.

[38] A. Garner, A. Gholinia, P. Frankel, M. Gass, I. MacLaren, M. Preuss. The microstructure and microtexture of zirconium oxide films studied by transmission electron backscatter diffraction and automated crystal orientation mapping with transmission electron microscopy. Acta Materialia, 80(2014): 159-171.

[39] P.W. Trimby, Y. Cao, Z. Chen, S. Han, K.J. Hemker, J. Lian, X. Liao, P. Rottmann, S. Samudrala, J. Sun, J.T. Wang. Characterizing deformed ultrafine-grained and nanocrystalline materials using transmission Kikuchi diffraction in a scanning electron microscope. Acta Materialia, 62(2014): 69-80.

[40] W. Zieliński, T. Płociński, K.J. Kurzydłowski. Transmission Kikuchi diffraction and transmission electron forescatter imaging of electropolished and FIB manufactured TEM specimens. Materials Characterization, 104(2015): 42-48.

[41] P.M. Scott, M. Le Calver. "Some possible mechanisms of intergranular stress corrosion cracking of alloy 600 in PWR primary water". In Proceedings of the sixth international symposium on environmental degradation of materials in nuclear power systems-water reactors, (TMS, 1993), 657-665.

[42] H.K. Birnbaum, P. Sofronis. Hydrogen-enhanced localized plasticity - a mechanism for hydrogen-related fracture. Materials Science and Engineering: A, 176(1994): 191-202.

[43] F. P. Ford. Quantitative prediction of environmentally assisted cracking. Corrosion, 52 (1996): 375-395.

[44] T. Magnin, A. Chambreuil, B. Bayle. The corrosion-enhanced plasticity model for stress corrosion cracking in ductile fcc alloys. Acta Materialia, 44(1996): 1457-1470.

[45] K. Arioka, T. Yamada, T. Miyamoto, M. Aoki. Intergranular Stress Corrosion Cracking Growth Behavior of Ni-Cr-Fe Alloys in Pressurized Water Reactor Primary Water. Corrosion, 70(2014): 695-707.

[46] ] B. Langelier, S. Y. Persaud, A. Korinek, T. Casagrande, R. C. Newman, G. A. Botton. Effects of boundary migration and pinning particles on intergranular oxidation revealed by $2 \mathrm{D}$ and $3 \mathrm{D}$ analytical electron microscopy. Acta Materialia, 131 (2017): 280-295.

[47] J. Dohr, D.E. Armstrong, E. Tarleton, T. Couvant, S. Lozano-Perez. The influence of surface oxides on the mechanical response of oxidized grain boundaries. Thin Solid Films, 632(2017): 17-22.

[48] K. Fujii, T. Miura, H. Nishioka, K. Fukuya. Degradation of grain boundary strength by oxidation in alloy 600. Materials transactions, 52(2011): 1447-1458.

[49] E. A. West, G. S. Was. Strain incompatibilities and their role in intergranular cracking of irradiated 316L stainless steel. Journal of Nuclear Materials, 441(2013): 623-632.

[50] S. Lozano-Perez. A guide on FIB preparation of samples containing stress corrosion crack tips for TEM and atom-probe analysis. Micron, 39(2008): 320-328.

[51] S. Lozano-Perez, J. Dohr, M. Meisnar, K. Kruska. SCC in PWRs: learning from a bottom-up approach. Metallurgical and Materials Transactions E, 1(2014): 194-210.

[52] S. Lozano-Perez, T. Yamada, T. Terachi, M. Schröder, C. A. English, G. D. W. Smith, C. R. M. Grovenor, 
B. L. Eyre. Multi-scale characterization of stress corrosion cracking of cold-worked stainless steels and the influence of Cr content. Acta Materialia, 57(2009): 5361-5381.

[53] G.C. Wood, F.H. Stott, D.P. Whittle, Y. Shida, B.D. Bastow. The high-temperature internal oxidation and intergranular oxidation of nickel-chromium alloys. Corrosion Science, 23(1983): 9-25.

[54] D.P. Whittle, Y. Shida, G.C. Wood, F.H. Stott, B.D. Bastow. Enhanced diffusion of oxygen during internal oxidation of nickel-base alloys. Philosophical Magazine A, 46(1982): 931-949.

[55] S. M. Bruemmer, M. J. Olszta, N. R. Overman, M. B. Toloczko. "Microstructural effects on stress corrosion crack growth in cold-worked Alloy 690 tubing and plate materials". 16th Int. Conf. on Environmental Degradation of Materials in Nuclear Power Systems - Water Reactors, Asheville, NC, 2013. [56] T. Moss, G. S. Was. "Accelerated stress corrosion crack initiation of Alloy 690 and Alloy 600 in high temperature hydrogenated water". 16th Int. Conf. on Environmental Degradation of Materials in Nuclear Power Systems - Water Reactors, Asheville, NC, 2013.

[57] K. Arioka, T. Yamada, T. Terachi, T. Miyamoto. Dependence of stress corrosion cracking for cold-worked stainless steel on temperature and potential, and role of diffusion of vacancies at crack tips. Corrosion, 64(2008): 691-706.

[58] K. Arioka, T. Miyamoto, T. Yamada, M. Aoki. Role of cavity formation in crack initiation of cold-worked carbon steel in high-temperature water. Corrosion, 69 (2013): 487-496

[59] S. Lozano-Perez, K. Kruska, I. Iyengar, T. Terachi, T. Yamada. The role of cold work and applied stress on surface oxidation of 304 stainless steel. Corrosion Science, 56(2012): 78-85.

[60] T. Terachi, T. Yamada, T. Miyamoto, K. Arioka. SCC growth behaviors of austenitic stainless steels in simulated PWR primary water. Journal of Nuclear Materials, 426(2012): 59-70. 